This PDF is a selection from an out-of-print volume from the National Bureau of Economic Research

Volume Title: Tax Policy and the Economy, Volume 11

Volume Author/Editor: James M. Poterba, editor

Volume Publisher: MIT

Volume ISBN: 0-262-16167-2

Volume URL: http://www.nber.org/books/pote97-1

Conference Date: October 22, 1996

Publication Date: January 1997

Chapter Title: Health Expenditure Persistence and the Feasibility of Medical Savings Accounts

Chapter Author: Matthew J. Eichner, Mark B. McClellan, David A. Wise

Chapter URL: http://www.nber.org/chapters/c10906

Chapter pages in book: (p. 91 - 128) 


\section{HEALTH EXPENDITURE PERSISTENCE AND THE FEASIBILITY OF MEDICAL SAVINGS ACCOUNTS}

\section{Matthew J. Eichner MIT}

\section{Mark B. McClellan}

Stanford University and NBER

\section{David A. Wise}

Harvard University and NBER

Prepared for the Tax Policy and the Economy Conference, Washington D.C., October 1996.

\section{EXECUTIVE SUMMARY}

Medical savings accounts (MSAs) have recently received considerable policy attention as an alternative approach to improving the efficiency of individual spending decisions for health care. The Health Insurance Portability and Responsibility Act includes specific tax incentives to support the use of MSAs on a limited basis beginning in 1997. We review the implications of such tax incentives for insurance and health care purchasing decisions. We

We acknowledge the support of the National Institute on Aging, the Commonwealth Fund, the Robert Wood Johnson Foundation, the Olin Foundation (McClellan) and the Hoover Institution (Wise). We are grateful to Nikhil Chanani and Victoria Stodden for research assistance, and to James Poterba for helpful comments on an earlier draft of this paper. 
then focus on a crucial equity consideration: the extent to which the feasibility of MSAs is limited by the persistence of medical expenditures over an individual's working life. We conclude that persistence does not present an overriding impediment to MSAs. Finally, we consider other key behavioral issues that will be important in evaluating such plans.

\section{INTRODUCTION}

Efforts in recent years to limit the growth in medical expenditures of the privately insured have relied primarily on managed care. Managed care plans feature various "supply-side" regulations and financial incentives for providers to limit excessive spending on medical care that might otherwise result from generous health insurance. The plans typically include low or negligible out-of-pocket payments by the insured. Indeed, current federal law prohibits health maintenance organizations from employing any substantial deductibles and copayments. The apparent success of these plans in controlling private-sector expenditure growth in recent years (Levit et al., 1996) has led many analysts to conclude that, despite administrative costs and interference in doctorpatient interactions at the time of illness, such "supply-side" methods may be the best means of avoiding many of the inefficiencies of health insurance (e.g., Zwanziger and Melnick, 1996).

Following Arrow (1963), however, a number of economists and policymakers, concerned perhaps with growing public or private regulation of medical care, have considered tax reforms to encourage more "demandside" incentives (Gramm, 1994; Feldstein and Gruber, 1995; Pauly and Goodman, 1995). To permit a trial of one such reform, the Health Insurance Portability and Availability Act of 1996, commonly known as the Kennedy-Kassebaum legislation, includes the establishment of tax incentives for medical savings accounts (MSAs) on a very limited basis, beginning in $1997 .{ }^{1}$

The principal motivation for MSA tax incentives is to make insurance plans with high deductibles and copayments more attractive to a larger number of Americans. Participation rates in such "catastrophic" or major-risk plans have usually been low, compared to traditional fee-forservice or managed-care plans, when offered by employers. There are several reasons for low participation. First, most individuals appear quite risk-averse in their preferences for health insurance. One important cause may be the minimal levels of liquid assets held by most households (see, e.g., Poterba, Venti, and Wise, 1996a), so that signifi-

1 HR 3103 in the 104th Congress, which was renamed the Health Insurance Portability and Availability Act, was signed by President Clinton in August 1996. 
cant uncertainty about out-of-pocket medical expenditures could be a daunting prospect. Second, the current tax treatment of health insurance favors low-deductible plans. Employer-provided health insurance is financed with pre-tax dollars, so that individuals are likely to choose more coverage than they would if they faced the full price of insurance. Moreover, because out-of-pocket payments for medical care are only deductible if they exceed $7.5 \%$ of income, tax law favors plans that minimize out-of-pocket payments. Favorable federal tax treatment of MSAs would counteract these obstacles to the purchase of health insurance with substantial out-of-pocket payments. ${ }^{2}$

An MSA is a tax-favored individual or family savings account intended primarily as a reserve for medical spending. The MSA is typically coupled with an insurance plan that covers very large medical expenditures only; smaller expenditures are paid for out of the MSA. Assets remaining in the MSA at retirement, or when the insurance is superseded by Medicare at age 65, are available for other purposes, like general consumption in retirement. Because a larger share of their actual medical expenditures would be financed from their own savings, individuals would be more sensitive to costs of treatment over a larger range of expenditures. An MSA thus combines the desirable features of catastrophic coverage for reducing medical expenditures with a mechanism that creates a reserve for paying individual expenses. Thus an MSA coupled with a catastrophic insurance plan may reduce medical expenditures and encourage saving. To the extent that catastrophic insurance costs less than more generous plans, the MSA will also induce lower insurance costs.

In this paper, we analyze MSAs in some detail. In the next section, we illustrate how the MSAs envisioned in the Kennedy-Kassebaum legislation would work in practice. We describe the important features of MSA tax incentives, and then discuss how these incentives might affect individual behavior. In section three, we consider a critical issue that is likely to determine the ultimate success of MSA plans in promoting more efficient use of health care. We emphasize the potential implications of persistence in individual medical expenditures and the resulting equity implications of MSAs for individuals covered over long time periods.

Long-term accumulations in MSAs will only be equal across individuals if they are fully insured against medical expenses-which encour-

2 At least 13 states have already enacted tax breaks for MSAs, but these reforms have involved much lower state marginal tax rates. Existing federal law also allows employers to establish "flexible spending accounts," which permit employees to use pretax dollars for out-of-pocket medical expenditures. However, balances not spent at the end of the year are lost, so that employees tend to rely on them in a limited way for predictable expenses only. 
ages inefficient use of medical care-or if the individual illnesses and associated medical care expenditures average out over time. In any given year, only a small minority of non-elderly individuals face major illnesses. If the same individuals are likely to be ill year after year, MSAs could result in large differences in accumulations in MSAs. On the other hand, if different individuals experience health shocks randomly over time, MSA balances would not accumulate unevenly despite the apparent lack of complete insurance at any point in time. In that case, over a longer time period or a working lifetime, an MSA plan would provide relatively desirable incentives to use medical care, yet would not generate substantial inequality in MSA accumulations.

Because individual health shocks clearly vary, the feasibility of an MSA plan depends on whether the gains (improved incentives for efficient health care spending and increased savings) outweigh the costs (more variation in individual health care expenses) than under more generous insurance plans. Indeed, the problem of persistence in health care expenditures, and the resulting selection of the healthy into MSAs, has been a frequent criticism of MSA plans (e.g., Moon, Nichols, and Wall, 1996). Our results suggest that, at least for the vast majority of the employed non-elderly population, persistence is not so extreme as to make such plans infeasible.

Many other complex issues surround the design and implementation of an MSA-based insurance scheme, or any other health insurance reform designed to make individuals more financially sensitive to their medical choices. In the fourth section of the paper, we review the implications of some of these issues for the success of MSA-based insurance reforms. In general, these issues involve empirical questions about the likely magnitudes of desirable and undesirable effects of MSAs offered together with alternative insurance plans. For the moment, insufficient evidence exists to reach firm conclusions about many of them. In the concluding section, we consider whether and how the MSA experiment envisioned in the Kennedy-Kassebaum legislation may help shed light on these issues.

\section{AN INTRODUCTION TO MSAS}

\subsection{Features of an MSA Plan}

The Health Insurance Portability and Availability Act (HIPAA) includes provisions to allow a limited test of tax incentives for the establishment of MSAs. This legislation can be used to illustrate some of the key features of MSAs and their associated catastrophic insurance plans, and the taxincentives for their use. In subsequent sections, we explore the implications of MSA reforms for equity and efficiency in the health care sector. 


\subsubsection{Restrictions on Eligible Health Insurance Plans To prevent indi-} viduals from using the MSA simply as a tax break in conjunction with traditional health insurance, thereby defeating the purpose of the tax incentives, MSA tax incentives must be accompanied by restrictions on the maximum generosity of the associated health insurance plan. Conversely, if no minimum generosity of the associated plan were required, enrollees might be encouraged to rely on charity care or publiclyprovided health care in the event of a major illness. In the HIPAA, eligible plans for individuals must include a deductible of at least $\$ 1,500$ and no more than $\$ 2,250$, and an out-of-pocket maximum (OPM) of no more than $\$ 3,000$. For family MSAs, the allowable deductibles range from $\$ 3,000$ to $\$ 4,500$ and the OPM is $\$ 5,500$. Federal restrictions on the financial liability that managed-care plans may impose on enrollees will prevent health maintenance organizations from offering MSA-eligible plans under the HIPAA. However, it is easy to imagine "combination" MSAs that are purchased in conjunction with managed-care plans that feature substantial out-of-pocket payments for medical services. If MSAs do become more popular, the emergence of combined plans might be expected on the basis of both self-selection (e.g., individuals with low risk of mental illness might not want to pay for a plan that provides unlimited catastrophic coverage for mental illness) and efficiency (e.g., managed care for mental illness may do a better job of targeting psychiatric care to individuals for whom it is worthwhile than high deductibles).

\subsubsection{Tax Treatment of MSA Contributions, Accumulations, and Bal-} ances The tax-favored status of MSA contributions might consist of either a tax deduction, as is accorded to traditional health insurance, or a tax credit. Because the value of a deduction increases with the marginal tax rate, it is more valuable to higher-income families. The tax incentive might involve MSA contributions, earnings on MSA balances, or the MSA balance itself. ${ }^{3}$ The HIPAA allows tax-deductible contributions of up to $65 \%$ of the insurance plan deductible for an individual MSA and $75 \%$ of the insurance plan deductible for a family MSA in each year. The MSA earnings are not taxed on accrual, and there is no maximum amount beyond which a tax on the MSA balance is imposed.

2.1.3 Tax Treatment of MSA Withdrawals Most MSA plans also envision tax-favored status for MSA withdrawals for medical expenses, and penalties for withdrawals for nonmedical use. These features are not required but obviously strengthen the tax incentive to use an MSA for

${ }^{3}$ Pauly (1994) discusses these tax issues in detail. 
medical care. The definition of medical expenses in the HIPAA is based on current IRS law, and thus includes many types of expenditures such as eyeglasses, dental care, rehabilitation, mental health care, and other services that are not covered generously by most health insurance plans today. Withdrawals from the MSA for nonmedical spending are treated as taxable income and also face an additional $15 \%$ tax penalty under the HIPAA. However, individuals can make withdrawals for nonmedical uses without penalty beginning at age 65 or if disability occurs, and balances at death are not subject to tax penalties.

\subsubsection{Obstacles to Switching Out of the MSA Some medical expenditures} are predictable (e.g., a woman who is or expects to become pregnant may join a plan with generous maternity coverage in that year), and the timing of some discretionary expenditures may be adjusted based on taxand insurance incentives (e.g., an individual with osteoarthritis may postpone a joint replacement operation until he can join a plan with a relatively low deductible). Features to discourage such switching once an individual is enrolled in an MSA include longer "lock-in periods" (e.g., requirements of advance notice of one or more years before leaving the plan) and tax incentives (e.g., prohibitions against rolling over MSA balances into subsequent insurance purchases). Such obstacles imply larger long-term financial risks, which may discourage enrollment. We consider the likely magnitude of long-term financial risks in the next section. The HIPAA does not include explicit lock-in periods, but it does not allow MSA funds to be used to purchase a noneligible plan without penalty. Thus, an individual who decides to switch out of the MSA would have to treat the remaining MSA balance as taxable income, with the $15 \%$ penalty. ${ }^{4}$

2.1.5 Choice Restrictions Concerns about the self-selection of healthy individuals into MSAs have led to some proposals to restrict or require the availability of certain alternative plan choices in conjunction with the MSA. Clearly, the selection of only the healthy members of a firm or other population into an MSA could be eliminated by requiring all prospective enrollees to join. Alternatively, to limit the financial liability of individuals with chronic illnesses who have persistently high demands for health care, a firm or the government could establish a subsidy for individuals with certain chronic illnesses, paid for by healthier individuals. The HIPAA does not include any restrictions on the set of plan choices that individuals or employees may be offered as alternatives to

4 In addition, as we discuss in Section 4, simply having an existing MSA balance creates a lockin effect; it is easier to get individuals to stay than to join. 
MSAs, and such restrictions do not appear likely in any further insurance reforms in the near future. As we discuss below, however, the selection problem associated with MSA availability may not be as great as the selection problem when only managed-care plans are available.

2.1.6 Eligible Persons MSA tax incentives could be offered to the whole population, the nonelderly population, or particular subgroups; tax incentives could also differ according to patient health characteristics (e.g., disability) or income characteristics. Because the MSA component of the HIPAA was explicitly designed as a limited MSA trial, enrollment is open only to firms that averaged 50 or fewer employees in either of the preceding two years, and to the self-employed. These individuals are less likely to be covered by generous indemnity or managed-care plans, and so might be expected to find managed-care plans more appealing. In addition, the small size of their risk pools suggests that offering MSAs could not do much to worsen any problems of adverse selection in these small groups. The HIPAA also caps total enrollment in MSAs at 750,000 accounts, ${ }^{5}$ and only provides for new MSA plans to be available from 1997 to 2000 . The bill also excludes the elderly. In Section III, we consider some implications of these substantial limitations on availability for what may be learned from the MSA trial.

\subsection{Incentive Effects of MSAs}

A brief description of the incentives to use medical care in an MSA compared to other types of health insurance illustrates the potentially important behavioral responses to this new tax policy. It also provides a foundation for describing the distinctive features of self-selection into health plans that may arise when an MSA choice is available. Figure 1 plots an individual's out-of-pocket medical expenses as a function of his or her total medical expenditures in two alternative health plans. For reference, the ray OA plots total medical expenditures in the absence of any insurance or tax deductibility. An illustrative "traditional" insurance plan features a $\$ 250$ deductible and $20 \%$ copayment up to a $\$ 1000$ out-of-pocket maximum. An illustrative catastrophic insurance plan, which would fall within HIPAA requirements for use in conjunction with an MSA, features a $\$ 2000$ deductible. ${ }^{6}$ In the traditional plan, individuals bear the full cost of their first $\$ 250$ of expenses (OB), then face a price of 0.2 times the price of medical care for their next $\$ 3750$ of

5 Actual enrollment might substantially exceed 750,000 because MSA availability will end only in the year after the cap is exceeded.

${ }^{6}$ MSA-associated plans may also include copayments after the deductible is met; for simplicity, we do not illustrate such a plan here. 


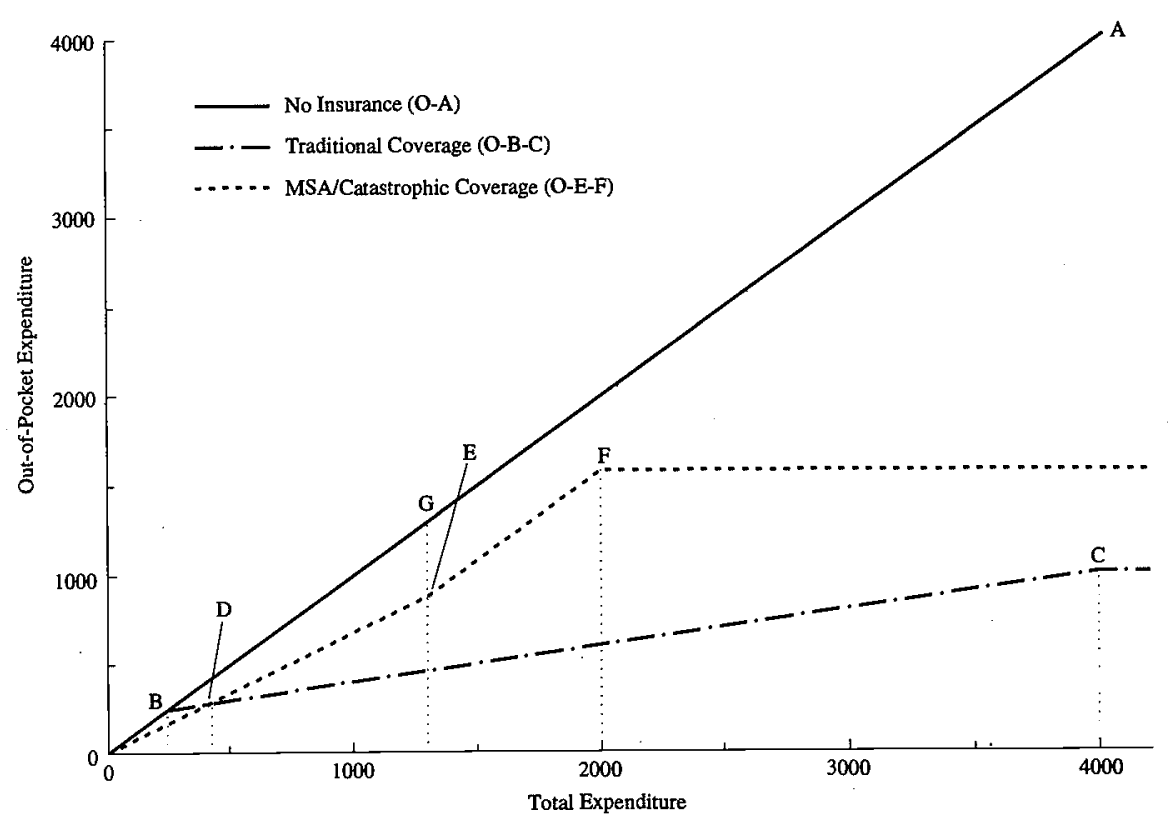

FIGURE 1: Comparison of Illustrative Plans

medical expenditures (BC, the copayment range), and then face a price of zero for expenditures after they reach the out-of-pocket maximum (OPM).

Because medical expenditures from the MSA are deductible, individuals who have positive but low medical costs face a lower (after-tax) cost than they would in the traditional plan. Suppose that the individual in our illustrative case has a marginal tax rate of 0.33 . Then her net out-ofpocket payments are lower over a range (OD) of low expenses; in this example, point D occurs at an expenditure level of approximately $\$ 450 .^{7}$ A higher deductible in the alternative plan or higher marginal tax rate would cause point $D$ to shift to the right, making the MSA appear even more favorable for those expecting low expenditures. ${ }^{8}$

Assume for the moment that the MSA enrollee had no existing MSA balance prior to making the full amount of the tax-deductible contribu-

7 That is, expenditures under the alternative plans are equal at the level $x$ such that $0.67 x=$ $250+0.2(x-250)$.

${ }^{8}$ Under current tax law, MSAs are even more favorable because of the "medical" expenditures described previously that are not generally covered under traditional plans but that would be deductible in the MSA. For example, individuals expecting high rehabilitation expenditures might find an MSA particularly attractive. 
tion in the current year. The HIPAA allows MSA contributions in this case of up to $\$ 1300$ (that is, $\$ 2000 \times 0.65$ ); thus, the individual's medical expenses remain subsidized by her marginal tax rate up to $\$ 1300$ (the range OE). Spending beyond $\$ 1300$ up to the plan's OPM is not subsidized; over this range, the individual bears the full cost of medical expenses (EF). If an MSA balance of at least $\$ 700$ was carried over from the previous year, of course, medical expenses would be tax-subsidized up to the plan's out-of-pocket maximum. Thus, the individual's maximum after-tax payments under the $\$ 2000$-deductible MSA plan would be $\$ 1571$ ( $\$ 1340$ if her initial MSA balance was at least $\$ 700$ ). The area OEG represents the tax expenditure associated with the deductibility of MSA withdrawals. Remaining expenditures beyond $\$ 2000$ are fully covered by the catastrophic plan.

For individuals expecting high medical expenditures, just as for individuals expecting very low medical expenditures, a higher marginal tax rate or lower out-of-pocket maximum in the catastrophic plan makes it appear more attractive relative to the alternative traditional plan. For example, suppose that the plan's out-of-pocket maximum was $\$ 1500$ (also an allowable plan under the HIPAA), and consider the after-tax liability of an individual expecting medical expenses over $\$ 4000$. Then, if the individual had a balance of at least $\$ 525$ in the MSA at the beginning of the year, her after-tax medical expenditures would be the same in the MSA plan as in the traditional plan; if she had no initial balance but a marginal tax rate of at least 0.513 , she would still face lower after-tax liability in the MSA plan.

These medical expenditure comparisons have not considered the difference in premium prices. Because the catastrophic plan features insurance payments that are the same or much lower than the alternative plan at most expenditure levels, ${ }^{9}$ the traditional-plan premium is likely to be higher, perhaps much higher. Thus, even in the original example $(\$ 2000$ deductible), an individual expecting very high medical expenditures might be better off choosing the MSA. ${ }^{10}$ MSA plans are not necessarily unattractive or risky to the chronically ill, particularly those with high

${ }^{9}$ In the example discussed in the text, for expenditures between $\$ 250$ and $\$ 2000$, the catastrophic plan pays zero while the traditional plan pays $80 \%$. For expenditures between $\$ 2000$ and $\$ 4000$, the catastrophic plan pays $100 \%$ while the traditional plan pays $80 \%$. Thus, at any level of medical expenditures above $\$ 250$, total plan payments will be higher in the traditional plan, and so a fair premium for a given individual would be higher in the traditional plan. We consider the effects of plan selection on the premiums momentarily.

${ }^{10}$ This would be the case if the alternative plan premium were at least $\$ 571$ higher, if the individual had no initial MSA balance, and at least $\$ 340$ higher if the individual had an initial balance of at least $\$ 700$. 
marginal tax rates and those whose alternative-plan choices are not very generous.

The persons who are most likely to be worse off in the MSA are those with low marginal tax rates and middle-range expenditures, for which the traditional plan provides substantial relief through copayments. For example, lower-income individuals who have frequent ambulatory medical care use, a single outpatient surgical procedure, or a brief hospital stay would likely face the greatest difference in out-of-pocket medical expenses under the MSA plan.

For most of the nonelderly today, the likely alternative to an MSA is not a "traditional" plan but a variety of managed-care plans. Such plans generally feature very low out-of-pocket payments, making them relatively attractive to individuals with high marginal tax rates compared to traditional plans with significant out-of-pocket payments. In this context, MSAs level the playing field (Pauly, 1994): the deductibility of MSA spending removes the tax wedge between choosing a plan that relies on "supply-side" versus "demand-side" incentives to limit medical expenditures. Removing the tax wedge in this way, rather than by limiting the deductibility of premiums for managed-care plans, comes at the expense of narrowing the tax base. Given the limited out-of-pocket liability in most plans offered by employers today, however, this narrowing may not impose a very high cost in tax expenditures.

Further, the low out-of-pocket liability of managed-care plans does not necessarily make them more attractive for those at high risk of a serious illness. Because they will tend to select a managed-care plan with higher-quality care, the premium of the plan they select is likely to reflect both the higher cost of providing this care and the selection of other relatively ill individuals into this plan. Relative to healthy individuals, these enrollees would place higher value on the lessrestricted care provided by catastrophic insurance should they become seriously ill.

Indeed, MSAs can provide a kind of "safety valve" to limit the extent of self-selection that can occur when a population with varying health risks chooses among more-generous and less-generous plans. Intuitively, the attractiveness of MSAs to low-risk and high-risk individuals compared to those with moderate health risks would appear to be a useful feature for limiting self-selection into plans.

Simulations by Nichols, Moon, and Wall (1996) provide quantitative support for this effect. Nichols et al. use representative U.S. data on the distribution of medical expenditures across employees to simulate the consequences of an employer offering a choice between a low-OPM traditional plan and a high-OPM MSA plan. Their high-OPM plan places 
the enrollee at risk of up to $\$ 750$ in additional out-of-pocket payments. ${ }^{11}$ They find that if individuals who actually have low expenditures enroll disproportionately in the MSA, the premium for the comprehensive plan may rise dramatically relative to the premium for the MSA plan. For example, if all those with low medical expenditures join the MSA, leaving only the "bad risks" in the traditional plan, then the premium difference between the plans would increase from approximately $\$ 600$ with no risk selection ( $\$ 1701$ for the traditional plan, $\$ 1110$ for the MSA plan) to over $\$ 6,000$ with massive adverse selection into the traditional plan.

Such large differences in premiums between the traditional and MSA plans are not sustainable. Not counting the tax subsidy for MSA spending, the heaviest users of medical care face a maximum out-of-pocket difference in expenditures between the two plans of only $\$ 750$, the difference in the OPMs. With the tax subsidy, this difference is even smallerperhaps not much larger than the original difference in premiums in the case of no selection. As soon as self-selection causes a premium difference of at least this magnitude to emerge, the sickest individuals in the population will join the healthiest in choosing the MSA plan.

The inclusion of an MSA option in a set of alternative plans differs in an important way from the health plan choices that most employees currently face, between managed-care plans that differ in quality or restrictiveness. Currently, there is little incentive for the most ill to join the plan chosen by the healthiest individuals in a group even if the premium difference becomes very large, because the low-quality plan does not subsidize high-quality intensive treatment regardless of the level of expenditures incurred. This absence of a safety valve can result in the "death spiral" of the premium of the most generous plan in a set of managed-care alternatives (e.g., Price and Mays, 1985). The fact that unrestricted catastrophic plans becomes attractive to the severely ill at only a moderate level of adverse selection into the more-generous plan restrains the premium spiral. The chronically ill would generally be better off if an employer offered a single plan that requires the entire population to pool together, but if that option is not available, an MSA may provide an effective bound on the magnitude of the selection problem. ${ }^{12}$

II In particular, they compared a "comprehensive" plan with a $\$ 250$ deductible and $\$ 1250$ OPM to an MSA plan with a $\$ 2000$ deductible, close to the comparison described in the text.

12 Note that the "safety valve" effect of an MSA plan only arises when the least-generous plan among the available choices is the MSA. In contrast, if the healthiest individuals could switch to an HMO of very low quality, they may not stay in the MSA plan along with the very ill. Even in this case, however, implementing an MSA along with imposing some restrictions on minimum HMO quality may reduce the extent of self-selection across plans compared to a set of managed-care alternatives alone. 
This discussion of the features of an MSA plan and their incentive consequences indicates that MSAs, at least as envisioned in the HIPAA, are unlikely to have truly catastrophic financial consequences for individuals at a point in time. Compared to the problems of high premiums caused by self-selection into managed care plans, the severely ill and others with high medical demands may not be that much worse off in an MSA plan in any given year, especially if they are in high tax brackets. In the next section, we evaluate the possible long-term consequences of MSAs for the distribution of medical expenses and savings accumulations.

\section{PERSISTENCE AND MSA FEASIBILITY}

Within the context of an illustrative MSA plan, we develop preliminary empirical evidence on the distribution of medical expenditures-and hence savings - under an MSA plan. Our analysis is based on longitudinal health insurance claims data from a large firm. In this analysis, we assume no behavioral response to the increased cost sharing under an MSA plan. We return to this important issue in the next section. To the extent that individuals respond to price incentives, expenditures will be more equal-perhaps substantially more equal-than our results suggest. Thus, our goal is to provide an upper bound on expenditure variation, as measured by variation in MSA accumulation. ${ }^{13}$

We first consider summary data on the persistence of medical expenditures. Then we describe the model that we have used to predict the distribution of "lifetime" expenditures and consider how well the model captures the distribution of actual expenditures. Finally, we present simulations of lifetime health care expenditures and MSA account balances at retirement.

\subsection{The Data}

The analysis is based on medical claims of employees in a large Fortune 500 manufacturing firm. We use all fee-for-service insurance claims over the three-year period 1989 through 1991 . Over this period approximately 300,000 employees and their dependents were covered through these insurance plans. All reported inpatient and outpatient medical expenditures for this population are included in our analysis. ${ }^{14}$

13 Much more detail on the evidence in this section is presented in Eichner, McClellan, and Wise (1996).

14 We do not include dental services, vision care, or outpatient pharmaceuticals, which account for approximately 15 percent of medical expenditures (Levit et al., 1996). Because these expenditures are relatively less concentrated in particular individuals than other inpatient and outpatient services, however, incorporating them would be unlikely to lead 


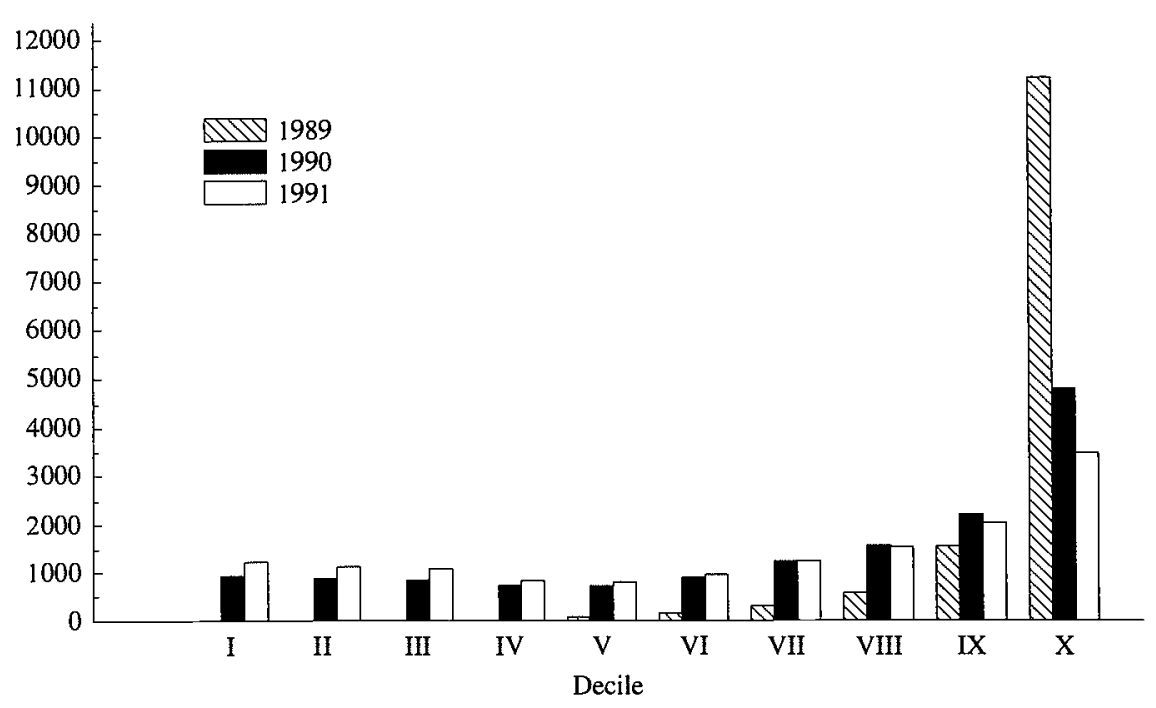

FIGURE 2: Mean Annual Expenditure (Persistence) by 1989 Decile

The firm has two relatively generous fee-for-service plans, one for hourly and another for salaried employees. The hourly plan, with benefits negotiated in union contracts, provides "first-dollar" coverage for virtually all health care. The salaried plan has an annual deductible of $\$ 200$ per individual and $\$ 250$ per family, a $20 \%$ coinsurance rate for all expenses, and an out-of-pocket annual limit (including the deductible) of $\$ 500$ per family. Both plans incorporate limited case management for certain high-cost medical conditions and concurrent review of hospital stays.

\subsection{Summary Descriptions of Persistence}

Do employees who had high expenditures in one year (in our example 1989) have high expenditures in subsequent years as well? This is called persistence. To begin, we have divided plan enrollees into deciles based on 1989 claims. Figure 2 shows average annual expenditures in 1989, in 1990, and then in 1991, all by 1989 expenditure decile. Consider employees who had expenditures in the top decile in 1989. In that year, their average expenditure was $\$ 11,249$. In the next year, their average expenditure was $\$ 4,786$ and two years later in 1991 they spent an average of

to a more concentrated distribution of medical expenditures in this population. Indeed, to the extent that such expenditures are not covered by traditional plans, their eligibility for MSA coverage would reduce individuals' net out-of-pocket medical expenses. 


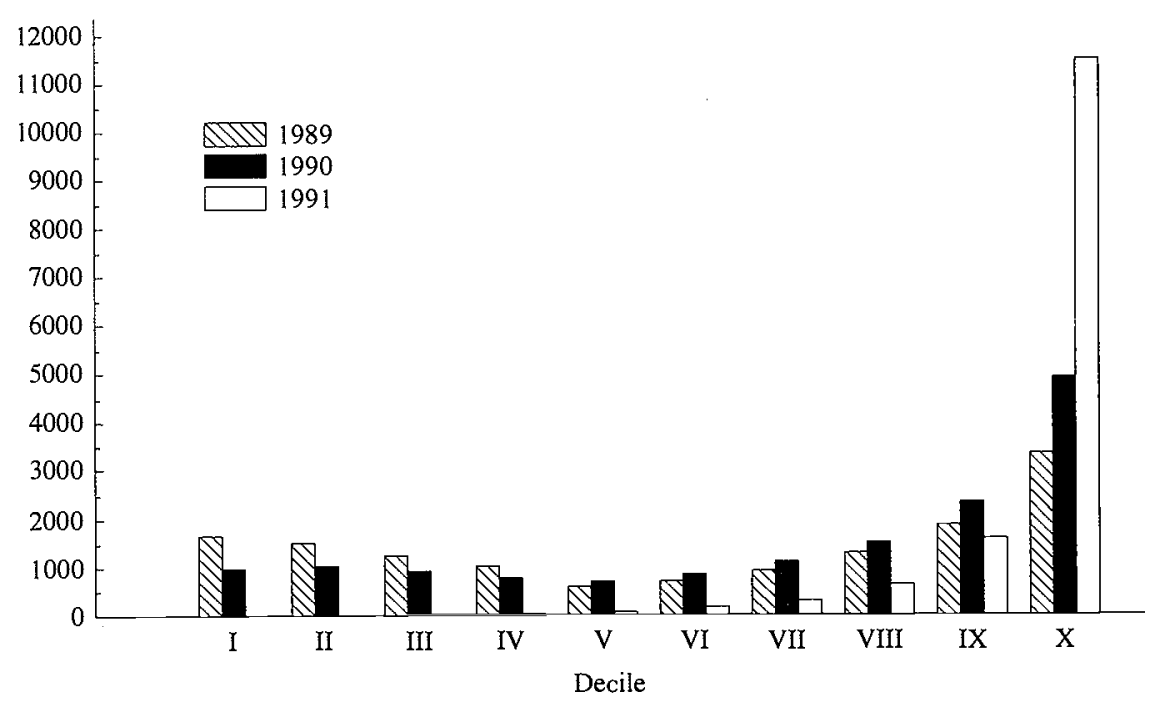

FIGURE 3: Mean Annual Expenditure (Persistence) by 1991 Decile

$\$ 3,489$. Persons in the tenth decile in 1989 spent over eight times as much as the average in that year. They spent close to five times the average in 1990 and almost three times the average in 1991. Thus these data show two important regularities: employees in the top decile continue to have expenditures well above the average over the next two years, but there is also a substantial, almost three-fold, decline in average expenditures over these three years for this group.

On the other hand, employees with the lowest expenditures in 1989 had higher expenditures in the next two years. For example, those in the bottom three deciles, who spent nothing in 1989, had expenditures near the average two years later in 1991. In all deciles, expenditures tend to gravitate toward the mean. Only in the top decile do expenditures remain substantially above the mean for three years.

Rather than considering the subsequent expenditures of employees conditional on expenditure level in 1989, an alternative is to consider previous expenditures conditional on expenditures in 1991. Figure 3 is analogous to Figure 2, but shows expenditures in 1989, 1990, and 1991, all by 1991 expenditure decile. What were the prior expenditures of employees in the top decile in 1991? Did they also have higher than average expenditures in the previous two years? The answer is yes, but whereas the expenditures of employees in the top decile in 1991 were approximately 8 times the average in that year, two years prior to that 


\section{TABLE 1}

Percent Distribution of 1989 and 1991 Expenditures.

\begin{tabular}{|c|c|c|c|c|c|}
\hline \multirow{2}{*}{$\begin{array}{l}\text { Expenditure } \\
\text { interval in } 1989\end{array}$} & \multicolumn{5}{|c|}{ Expenditure interval in 1991} \\
\hline & $\$ 0$ & $\$ 0-\$ 300$ & $\$ 300-\$ 1000$ & $\$ 1000-\$ 5000$ & Above $\$ 5000$ \\
\hline \multicolumn{6}{|c|}{ Joint distribution of 1989 and 1991 expenditures } \\
\hline$\$ 0$ & 8.89 & 13.66 & 5.39 & 3.45 & 1.72 \\
\hline$\$ 0-\$ 300$ & 15.03 & 8.58 & 4.29 & 2.62 & 1.24 \\
\hline$\$ 300-\$ 1000$ & 5.71 & 3.80 & 3.44 & 2.39 & 1.11 \\
\hline$\$ 1000-\$ 5000$ & 3.95 & 2.27 & 2.27 & 2.61 & 1.25 \\
\hline Above $\$ 5000$ & 2.12 & 0.95 & 0.89 & 1.20 & 1.17 \\
\hline \multicolumn{6}{|c|}{ Distribution of 1991 expenditures conditional on 1989 expenditures } \\
\hline$\$ 0$ & 26.84 & 41.27 & 16.28 & 10.43 & 5.19 \\
\hline$\$ 0-\$ 300$ & 47.33 & 27.02 & 13.50 & 8.24 & 3.91 \\
\hline$\$ 300-\$ 1000$ & 34.72 & 23.06 & 20.91 & 14.55 & 6.77 \\
\hline$\$ 1000-\$ 5000$ & 31.94 & 18.39 & 18.38 & 21.13 & 10.15 \\
\hline Above $\$ 5000$ & 33.50 & 15.01 & 14.09 & 18.90 & 18.49 \\
\hline \multicolumn{6}{|c|}{ Distribution of 1989 expenditures conditional on 1991 expenditures } \\
\hline$\$ 0$ & 24.89 & 46.69 & 33.10 & 21.13 & 26.42 \\
\hline$\$ 0-\$ 300$ & 42.10 & 29.32 & 26.34 & 21.31 & 19.11 \\
\hline$\$ 300-\$ 1000$ & 16.01 & 12.97 & 21.13 & 19.52 & 17.15 \\
\hline$\$ 1000-\$ 5000$ & 11.06 & 7.77 & 13.95 & 21.28 & 19.30 \\
\hline Above $\$ 5000$ & 5.94 & 3.25 & 5.48 & 9.76 & 18.02 \\
\hline
\end{tabular}

their average expenditure was only about 2.4 times the average. Similarly, persons with the lowest expenditures in 1991 had expenditures near the average two years earlier. Thus Figure 3 is almost the mirror image of Figure 2.

Another way to view persistence $\overrightarrow{i s}$ to consider the distribution of employees' expenditure intervals for two different years. Table 1 shows the distribution for 1989 and 1991 for all employees. Expenditures in each year are divided into five intervals, and three versions of the distribution are shown. The first panel shows the joint distributions of expenditures in the two years. For example, $8.89 \%$ of employees had zer̃o expenditures in both years, $15.03 \%$ had expenditures between $\$ 0$ and $\$ 300$ in 1989 and zero expenditures in 1991. (The percentages sum to 100 over all cells.) The most important part of this panel pertains to the fraction of employees who had high expenditures in both years. About $6.22 \%$ had expenditures above $\$ 1,000$ in both years, and only $1.17 \%$ had expenditures above $\$ 5,000$ in both years. Thus only a very small proportion of employees have high expenditures in one year as well as two years later or two years earlier.

The data also show persistence, consistent with the data in Figures 2 and 3. The second panel of Table 1 shows the distribution of 1991 expen- 
ditures by expenditure interval in 1989 . For example, $18.49 \%$ of persons who spent more than $\$ 5,000$ in 1989 also spent more than $\$ 5,000$ in 1991 , whereas only $5.19 \%$ of persons who had no expenditures in 1989 spent more than $\$ 5,000$ in 1991 . Rather than looking forward, as in the second panel, the third panel of Table 1 looks backward; it shows the distribution of 1989 expenditures by expenditure interval in 1991. Although only a small proportion of employees with expenditures above \$5,000 in 1991 also had high expenditures two years earlier in 1989, these employees are more likely to have had high expenditures two years earlier than were persons who had low expenditures in 1991 . For example, $18.02 \%$ of employees who spent more than $\$ 5,000$ in 1991 had also spent more than $\$ 5,000$ two years earlier, whereas only $3.25 \%$ of employees who spent nothing in 1991 had spent more than $\$ 5,000$ two years prior.

The features of the data described above are consistent with the known high concentration of medical expenditures in any given year. Although only a very small proportion of employees have high expenditures in the first and third years, for example, the mean expenditure among the top percentiles is very large. Thus in any one year, about $20 \%$ of enrollees in our sample account for about $90 \%$ of total health care costs. What our data allows, in contrast to cross-sectional data sources, is the analysis of individual expenditures over time. Even over a longer period of time, a small proportion of enrollees account for the bulk of expenditures. Again, this is because even over an extended period of time only a small proportion of enrollees have large expenditures, and thus the few that do account for a large fraction of the cost. We find that over a three-year period, $20 \%$ of employees account for about $80 \%$ of total cost. Based on the formal model predictions described below, we find that even over a working lifetime, about $20 \%$ of employees account for almost $50 \%$ of total costs.

\subsection{A Model of Expenditures}

Our goal is a formal description of medical expenditures that will allow us to simulate the pattern of expenditures over the working life, based on the persistence observed over three years. We begin with a description of the model and its use to predict expenditures. A critical feature of the model is the extent to which it captures actual expenditure patterns. Thus we give considerable attention to how well the model predictions capture the actual level and, most important, the actual distribution of health care expenditures. Finally, we describe the simulations of lifetime expenditures and MSA balances based on the model.

There are two critical aspects of health care expenditures that the model must capture. One is the relationship between expenditures in 
successive years, the persistence in expenditures. The other is the random shocks in health care expenditures that are not predicted by prior expenditures or by demographic variables. No matter what the expenditures of employees in prior years, there is an enormous variation in expenditures the next year. Thus enrollees with no expenditures in one year stand some change of having very high expenditures in the next year. Likewise, enrollees with very high expenditures in one year stand a good chance of having very low expenditures in the next year. Indeed, the lifetime distribution of expenditures is determined much more by these random shocks than by persistent expenditures that are predictable based on prior expenditures or demographic characteristics.

Because a large fraction of employees have no expenditures in a given year, it is useful to consider explicitly the expected value of expenditures in year $t M_{t}$, given by

$E\left(M_{t}\right)=\operatorname{Pr}\left[M_{t}=0\right] \times 0+\operatorname{Pr}\left[M_{t}>0\right] \times E\left(M_{t} \mid M_{t}>0\right)$

We estimate the independent components of this equation $-\operatorname{Pr}\left[M_{t}>0\right]$ and $E\left(M_{t} \mid M_{t}>0\right)$-separately. The probability of nonzero expenditures is estimated using a linear probability specification, and the level of expenditures given that expenditures are positive is estimated using a log linear regression. In both cases, the estimated relationship is of the form

$M_{t}=\alpha+\beta D+\gamma M_{\text {lag }}+\epsilon$

where medical expenditures in year $t, M_{t}$, are predicted by three factors: (1) demographic characteristics, denoted by $D$, and which include age, sex, and employment status (hourly or salaried); (2) past health care expenditures $M_{\text {lag }}$, which in this version include expenditures in years $t-1$ and $t-2$; and (3) random shocks $\in$.

The critical part of our analysis is the use of the resulting estimates to predict future expenditures. The "fit" of these predictions depends not only on our ability to model expected expenditures given an individual's characteristics, but also the distribution of shocks to expenditures. We want the distribution that is used in prediction to "match" the actual distribution as closely as possible, and this distribution is extremely skewed within any given cell of expenditures. We model this critical "error" component nonparametrically: instead of assuming a particular distribution for the random shocks $E$, we use the actual distribution of expenditure errors, given demographic characteristics and past expendi- 
tures. ${ }^{15}$ Thus, the method captures not only the average relationship between expenditures over time, but if high expenditures persist for some proportion of persons with a given set of demographic and past expenditure characteristics, then the model will also capture the proportion with high persistence. Predictions for years beyond year three are obtained by repeated applications of this procedure.

How could the predictions be improved? First, better predictors of expenditures (e.g., additional data on individual health characteristics and use of medical care) might improve the predictions of expected future expenditures, given past expenditure. For example, having a longer panel of claims data would permit us to construct groups with longer expenditure histories. ${ }^{16}$ We believe, however, that while a longer panel will allow a more accurate prediction of the pattern of regression to the mean after an expenditure shock, it would not have much effect on the overall persistence that the model now suggests. Second, we could augment our model with information from other sources on the relationship between medical care use over very long time periods. For example, are heart problems at age 50 preceded by high health care expenditures at age 30 ? No available panel of medical claims information can be used to determine directly whether such a relationship exists. However, we can observe expenditures in the next two years of persons that had high expenditures at age 30, as in the second panel of Table 1. And, going to older ages and looking backwards, we can observe the expenditures in the previous two years of persons who had high expenditures at age 50. Both of these approaches suggest that, for the most part, very high expenditures do not persist. Thus we believe that our predictions provide a good approximation to the distributions that would be observed in very long panels.

15 For example, consider the prediction of expenditures in the third year, given expenditures in the prior two years. The sample is divided into groups determined by age, sex, and employee status (hourly or salaried). Then within each of these groups the sample is further divided into 25 expenditure groups defined by expenditures in the prior two years. Now the prediction of expenditure in year three has two parts. First, the parameters estimated in equation (2) are used to predict mean expenditures in year three. This "systematic" part would show, for example, that enrollees with high expenditures in year one tended on average to have much lower expenditures two years later, as revealed in Figure 2. Second, a random shock is added to this systematic component. Within each cell, the random component is selected randomly from the actual distribution of residuals within that cell.

Suppose that the prediction is for enrollees who had high expenditures in years one and two. This method assures that if a given proportion of persons in this high expenditure cell have high expenditures in the third year, then our predictions will also show this same proportion (on average) to have high expenditures in the third year.

16 We are now constructing panel data with six years of expenditures rather than three. 


\subsection{Comparing Actual and Predicted Means and Distributions}

We first consider how well the model matches the actual subsequent mean expenditures of persons who had high expenditures in year one. For illustration we have chosen all persons aged 35 with expenditures over $\$ 10,000$ in 1989 . We then used the model to simulate their expenditures in the ten subsequent years. We compared the predictions in the subsequent two years with the actual data. For the first two years, for which we have matching actual data, the actual and simulated means are very close. The lag structure in the model is of course a way to extrapolate the decline in expenditures to future years. The simulations imply that after 4 or 5 years the expenditures of persons with large shocks approach the overall sample mean. The simulated and actual "decay" patterns are shown in Figure 4, along with a similar depiction for 45 year olds.

We also considered the future expenditures of persons with specific 1989 diagnoses that are typically associated with high expenditures, to determine if the expenditure pattern in these cases appeared consistent with the model's predictions. We considered the following diagnoses in 1989: Acute Myocardial Infarction (AMI), cancer, mental health (with inpatient care), and pregnancy. Only 45\% of 1989 AMI patients had expenditures greater than $\$ 1,000$ one year later in 1990 , only $34 \%$ had expenditures greater than $\$ 1,000$ two years later in 1991 . (Over $14 \%$ had zero expenditures in 1990 and $25 \%$ in 1991.) Less than $25 \%$ of cancer patients had expenditures over $\$ 1,000$ in 1990 and only $20 \%$ in 1991 . There was more persistence in the expenditures of inpatient mental health patients: $54 \%$ had expenditures over $\$ 1,000$ in 1990 and $42 \%$ in 1991. Pregnancy is one of the most important contributors to firm health care costs, but with minimal persistence. Only $17 \%$ of women with pregnancy-related diagnoses in 1989 had expenditures over $\$ 1,000$ in 1990 and only $13 \%$ in 1991 . We take these results as evidence that our simulated decay rates are not unreasonable. In particular, we find no reason to suspect that they are too rapid.

Second, we consider actual and simulated average expenditures by age for hourly and salaried men and women. The actual averages are based on the full sample of 230,497 . The simulated averages are determined as follows: begin with a sample of 1,000 employees age 25 . Then apply the prediction procedure described above-using equation (2) repeatedly and with random selection of residuals - to produce a stream of expenditures for each person through age 60 . The simulated averages for a given age are the averages of the simulated values at that age. The results for salaried men are shown in Figure 5. Because the simulated values are based on a rather small number of persons, there is more 
35 Year Olds with Expenses Above $\$ 10,000$
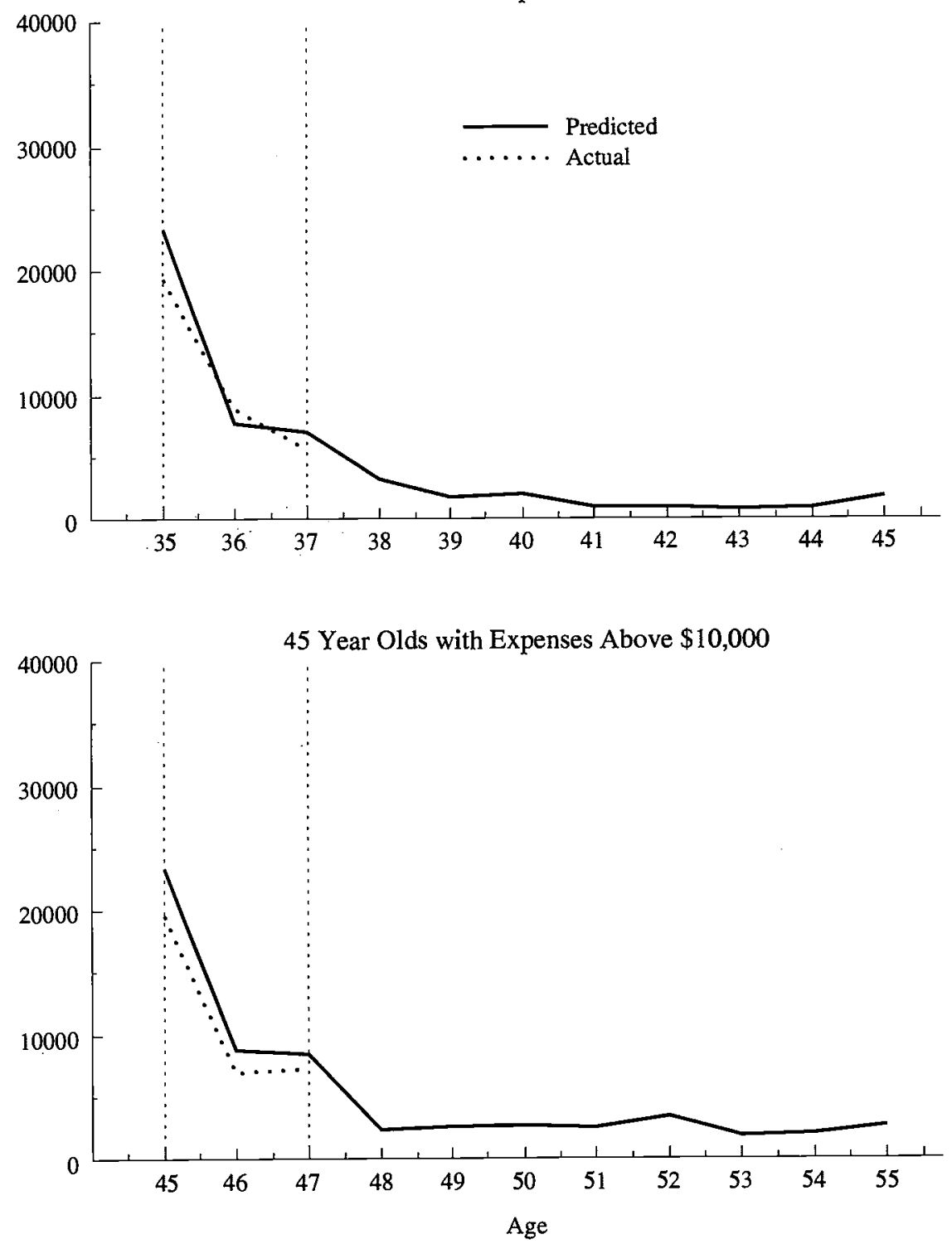

FIGURE 4: Decay Patterns Following Large Expenditures 


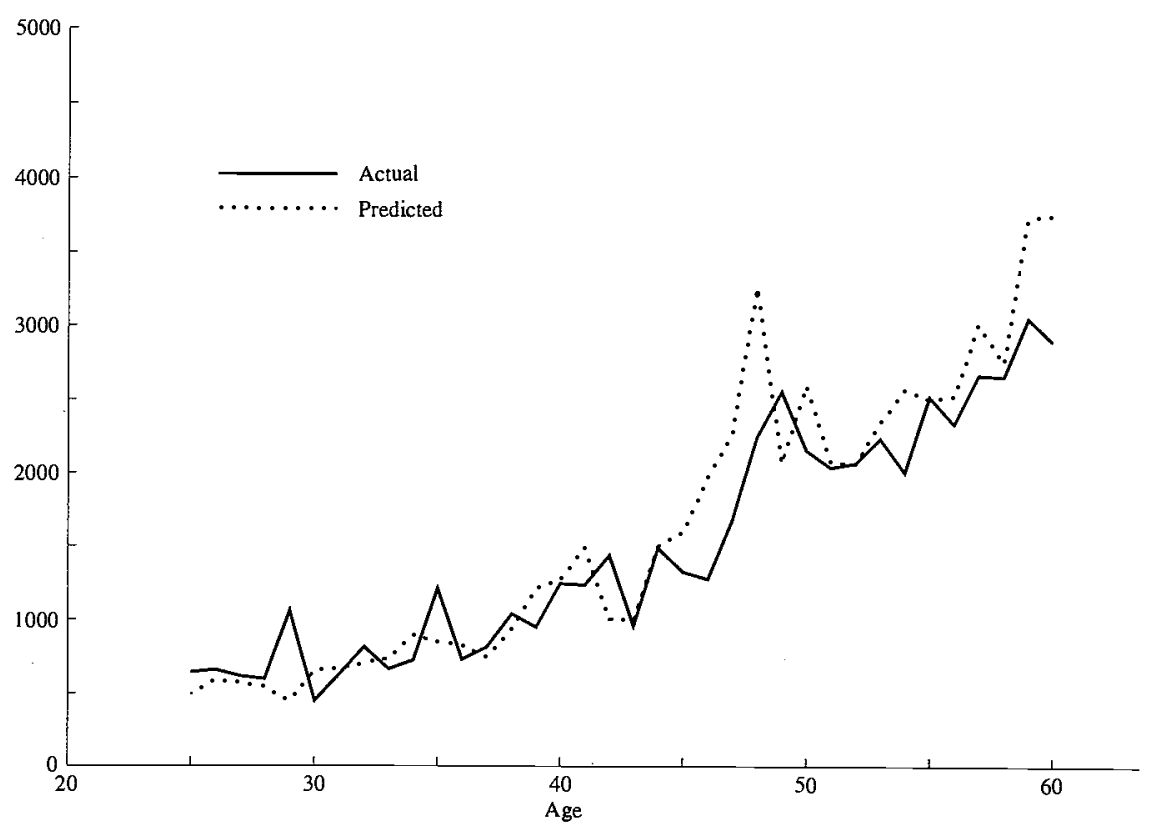

FIGURE 5: Annual Expenditures Salaried Males

variation in the simulated than the actual averages, but the overall match seems quite close. Results for other gender and employee groups are essentially the same.

Third, we consider how well the predicted distribution of expenditures in the third year, conditional on demographic variables and expenditures in the first and second years, matches the actual distribution in the third year. In particular, we were interested in determining whether our model underpredicted persistence. Such comparisons were made for persons at ages $30,40,50$, and 60 for hourly and salaried men and women. The actual and predicted distributions for persons age 60 are shown in Figure 6. Overall, the simulated and actual distributions are very similar. The results for the other age groups are essentially the same.

Fourth, we considered how well lifetime predictions, which produce levels and distributions of expenditures at each age, match actual levels and distributions observed at particular ages. Our subsequent simulations rest on the prediction of the expenditures of employees over a working lifetime. This comparison is intended to test the long-run implications of the model. We start with the expenditures of a sample of persons who are 25 in 1991. Then we simulate their expenditures 

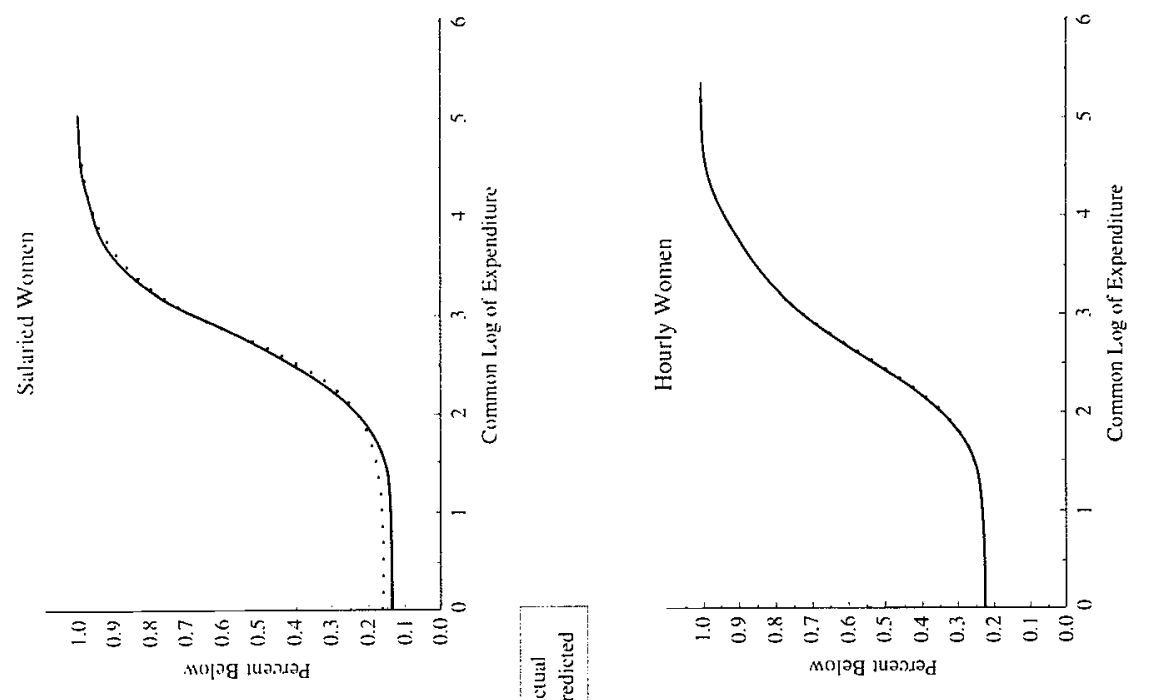

8
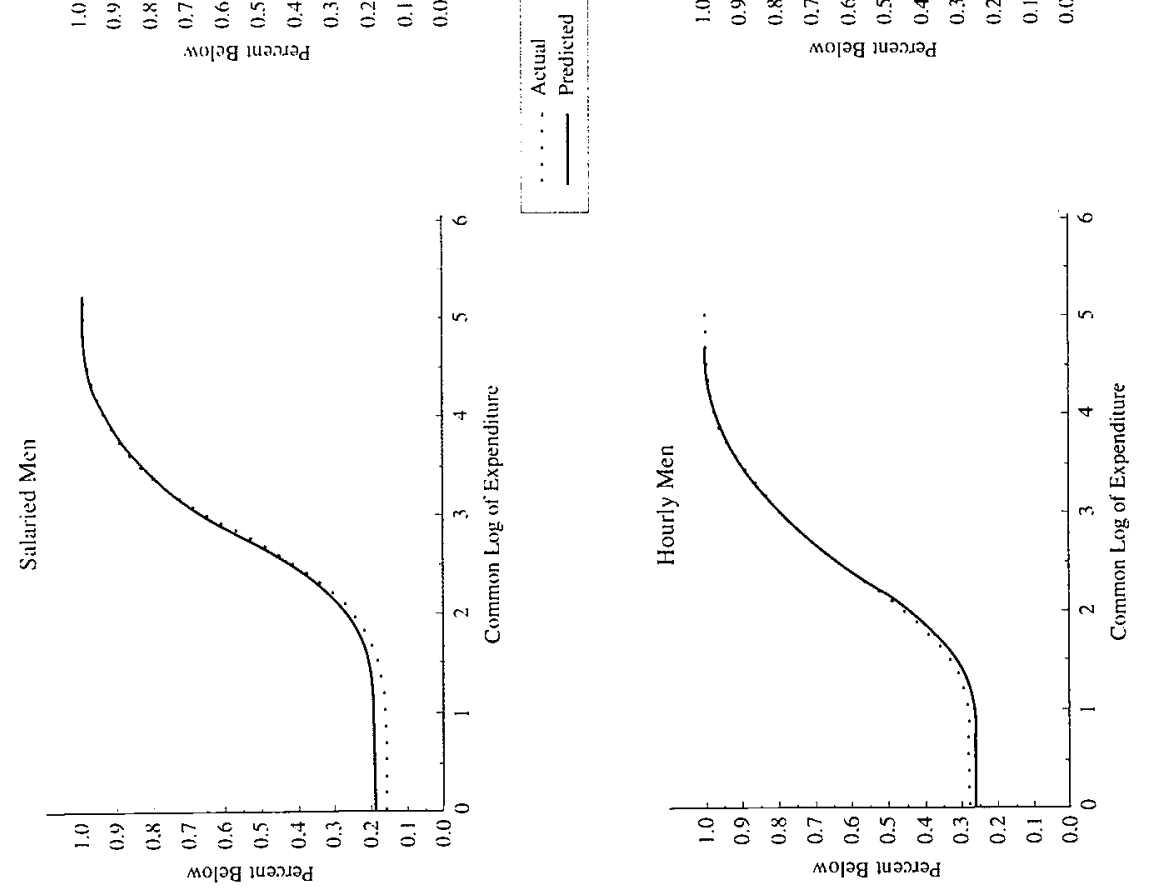



8 
through age 60 . We want to know in particular that the distribution of simulated expenditures approximates the actual distribution at older ages. Figures 7 shows simulated versus actual distributions at age 55 for hourly and salaried men and women. Overall, the distributions of simulated expenditures are very close to actual distributions. That is, starting with persons age 25 , repeated application of the model yields predicted expenditure distributions 30 years later-at age 55-that look very much like the actual distributions for persons who are now 55 . Given the small $(1,000)$ sample used for the simulations, simulations based on different samples yield somewhat different comparisons. But our general experience has been that there is no appreciable difference in the overall results.

\subsection{Simulated Lifetime Expenditures and MSA Balances}

We have simulated the lifetime expenditures of 1,000 employees who begin work at age 25 and retire at 60 . We realize that few, if any, persons would work for the same firm for that length of time, but it is the expenditure pattern that we want to capture, assuming that employees continued to use similar MSA plans.

The distribution of cumulative expenditures for salaried men at age 60 is shown in Figure 8, in which the logarithm of expenditure is shown. Translating to dollars, over a working lifetime, expenditures of salaried men vary from less than $\$ 10,000$ (about $10 \%$ of employees) to over $\$ 100,000$ (about $10 \%$ of employees). The median is about $\$ 32,000$. The distributions for the other gender and employee status groups are similar to those for salaried man.

Given the distribution of expenditures described above, how might an MSA plan work? We consider this plan:

The employer puts $\$ 2,000$ in each employee's MSA at the beginning of each year. ${ }^{17}$

The health insurance plan has a $\$ 4,000$ annual deductible, with expenses below the deductible paid by the employee (out of the MSA) and 100 percent of expenditures above the deductible covered by the health insurance plan. If the MSA balance goes to zero, all expenses are paid by the insurance plan.

17 We assume that employees do not withdraw from their MSA balances for other purposes, or contribute less than the full $\$ 2000$ in each year. This allows us to focus on the maximum variation in accumulation that is likely to result with this MSA plan. In practice, employees who accumulate relatively large savings "buffers" may be less likely to continue to contribute the full amount. This behavior would reduce the variation in accumulations in the MSAs and would not require employees to forgo as much current consumption. 

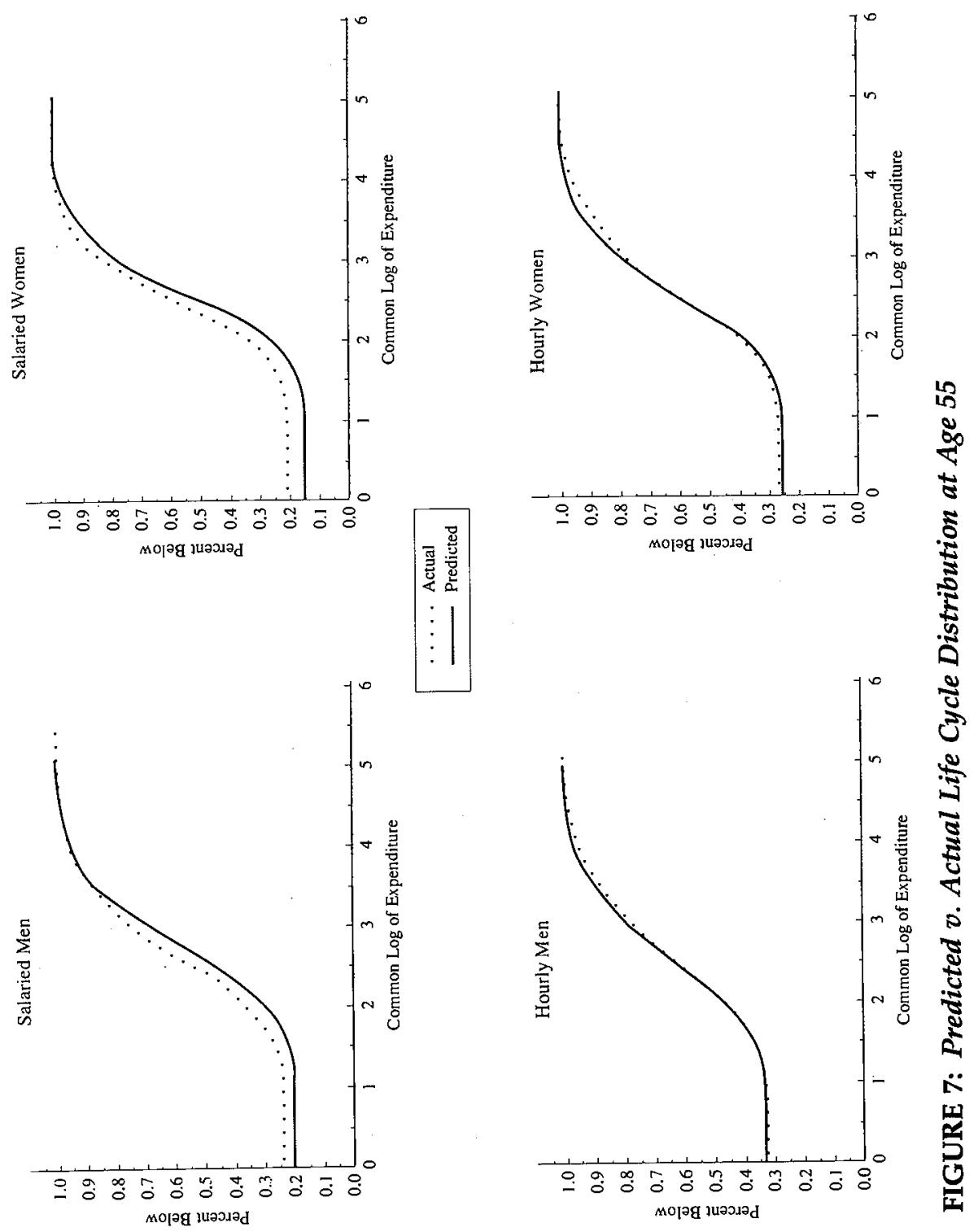


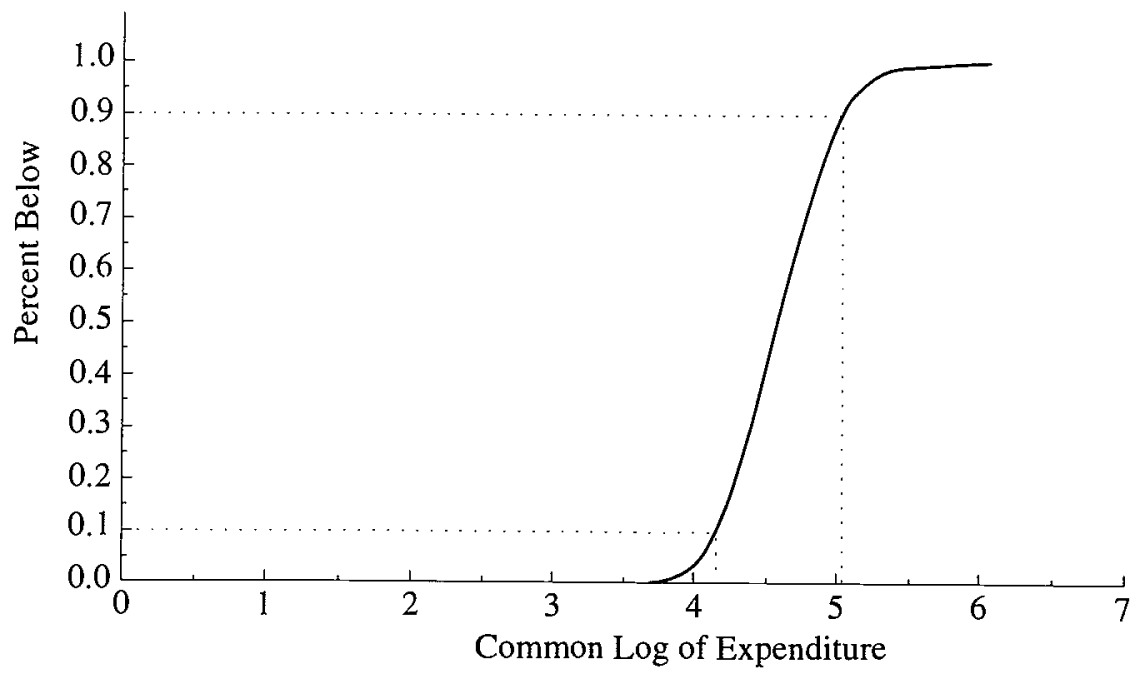

FIGURE 8: Simulated Distribution of Expenditures Salaried Males at Age 60

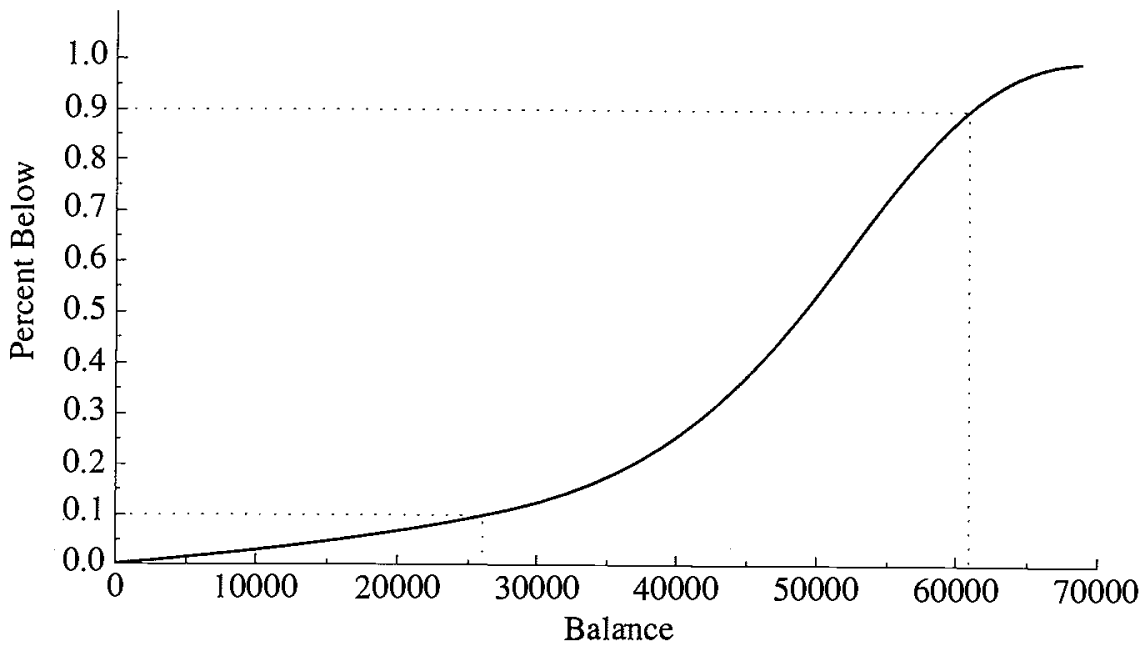

FIGURE 9: MSA Balances (Dollars) Salaried Males at Age 60 
The distribution of MSA balances for salaried men at age 60 is shown in Figure 9. After a working lifetime, most employees are left with a substantial accumulation. About $90 \%$ of the employees have a balance at age 60 that exceeds $\$ 25,000$, while $75 \%$ have more than $\$ 40,000$ and $50 \%$ have more than $\$ 50,000$. The distributions are similar for salaried women and for hourly employees.

Another way to understand the plan implications is to consider the proportion of MSA contributions that remain at selected ages. The distribution of this proportion for salaried men is shown in Figure 10. At retirement, only about $20 \%$ of employees have less than $50 \%$ of their contributions, about $10 \%$ have less than $35 \%$, and about $5 \%$ less than $20 \%$. And, $50 \%$ still hold more than $70 \%$ of their MSA contributions.

The average balance remaining in the MSA for salaried men is shown by age in Figure 11 . At age 60 , the average is about $\$ 46,000$. The amount by age can be compared to the 45 -degree line which represents the accumulation path if there were no withdrawals to cover health care costs. Although not precisely the same, the pattern is similar for salaried women and for hourly men and women.

\subsection{MSA Plans in the Health Insurance Portability and Availability Act}

The MSA provisions in the HIPAA are discussed in section 2 above. We have simulated two plans that are consistent with the HIPAA provisions and a third that is not strictly consistent with the Act. The first plan assumes that employees (in our firm) face a deductible of $\$ 1,500$ (and pay nothing above the deductible) and contribute $\$ 972$ each year to an MSA. The second plan assumes that employees face a deductible of $\$ 2,250$ (and pay nothing above the deductible) and contribute $\$ 1,463$ each year to an MSA. The average medical expenditure of employees in our firm is about $\$ 1,300$. Thus neither of these insurance plans provides truly catastrophic coverage only. The third plan we simulate features an annual deductible of $\$ 3,000$ and an annual MSA contribution of $\$ 1,950$. The out-of-pocket maximum of this plan is allowed in the HIPAA, but its deductible-limited to $\$ 2,250$ for individuals in the HIPAA-is higher than the allowable amount. We follow the HIPAA in setting the maximum annual MSA contribution to $65 \%$ of the deductible, so that our third plan includes a larger MSA contribution than the legislation permits. In addition, all of these simulations, including the KennedyKassebaum plans, assume that if the MSA is depleted, then all expenditures are paid by the insurance plan; this is not provided for in the Kennedy-Kassebaum bill. (Below, we show that out-of-pocket expenditures not paid from the MSA are very small.) 


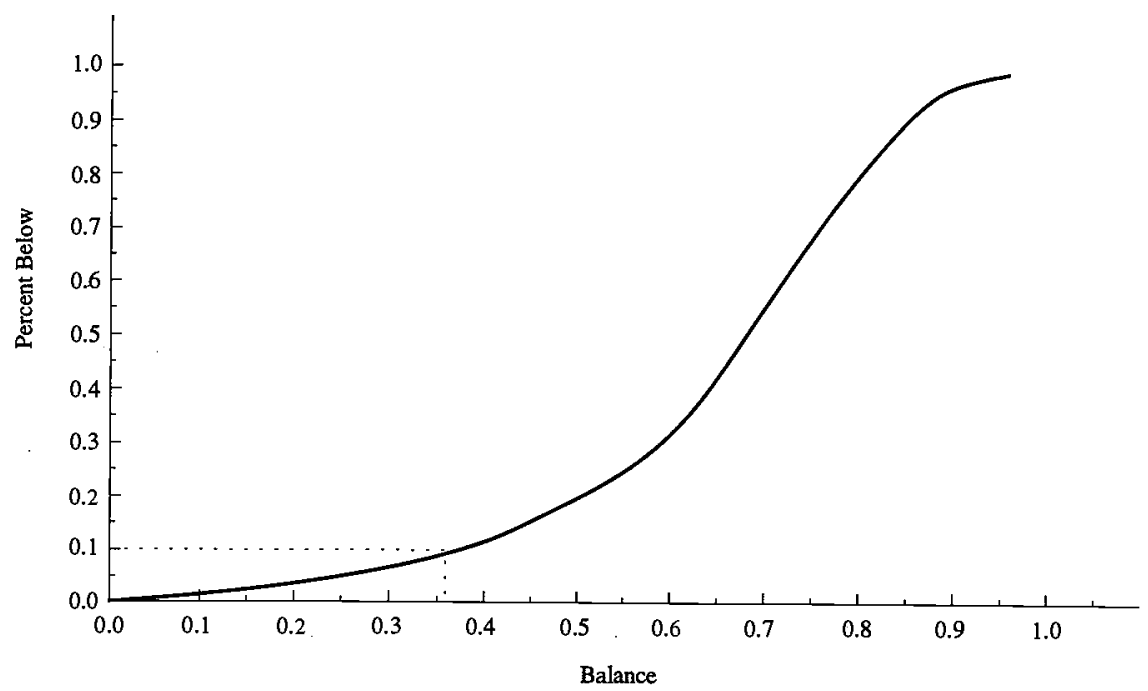

FIGURE 10: MSA Balances (Percent of Contributions) Salaried Males at Age 60

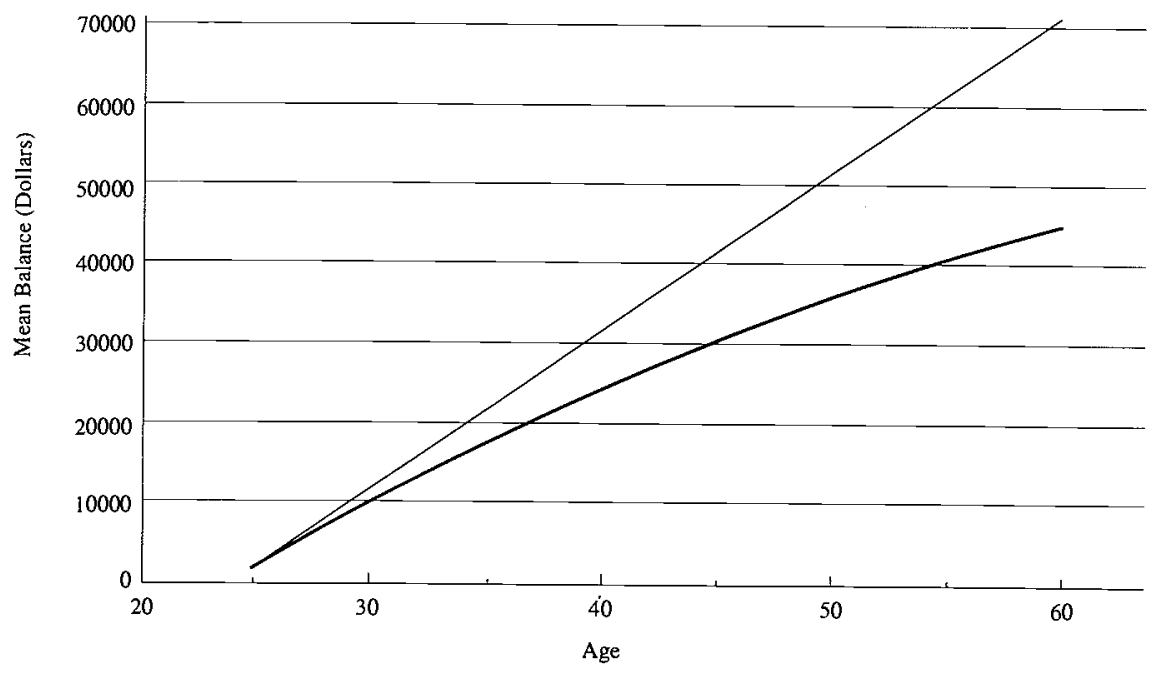

FIGURE 11: Mean MSA Balances by Age Salaried Males 


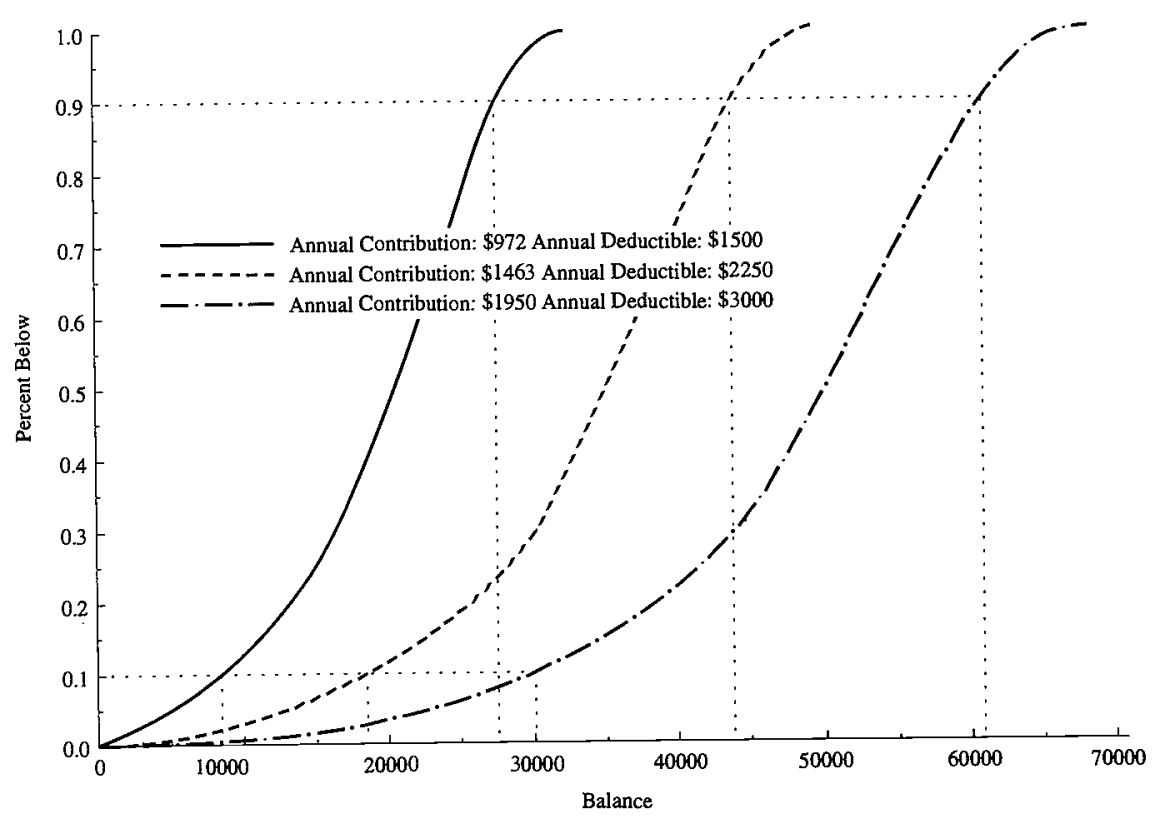

FIGURE 12: MSA Balances (Dollars) "Kennedy-Kassebaum" MSA Provisions Salaried Males at age 60

Figure 12 shows the distribution of MSA balances at age 60 for each of these versions. Figure 13 shows the distribution of the percent of lifetime contributions remaining in the MSA at age 60. (Figures 12 and 13 are analogous to Figures 9 and 10 respectively, which present the key results of our plan with a $\$ 4,000$ deductible and a $\$ 2,000$ annual MSA contribution.) Some key features of all four plans are summarized in Table 2. As in the EMW Base plan, in none of the Kennedy-Kassebaum plans do we find a large proportion of employees with extremely low balances, nor an extremely large proportion with very high balances. In particular, the differences between the balances of employees most likely and least likely to incur medical expenditures do not seem to us so great as to make such plans infeasible.

The distribution of expenditures is the same in each of the plans; no behavioral response is allowed in these simulations. Thus the balances remaining are simply the result of the MSA contributions and the insurance deductibles. Larger MSA contributions increase the remaining balance at retirement and larger insurance deductibles reduce the balance. The effect of different deductibles on the balance depends on the propor- 


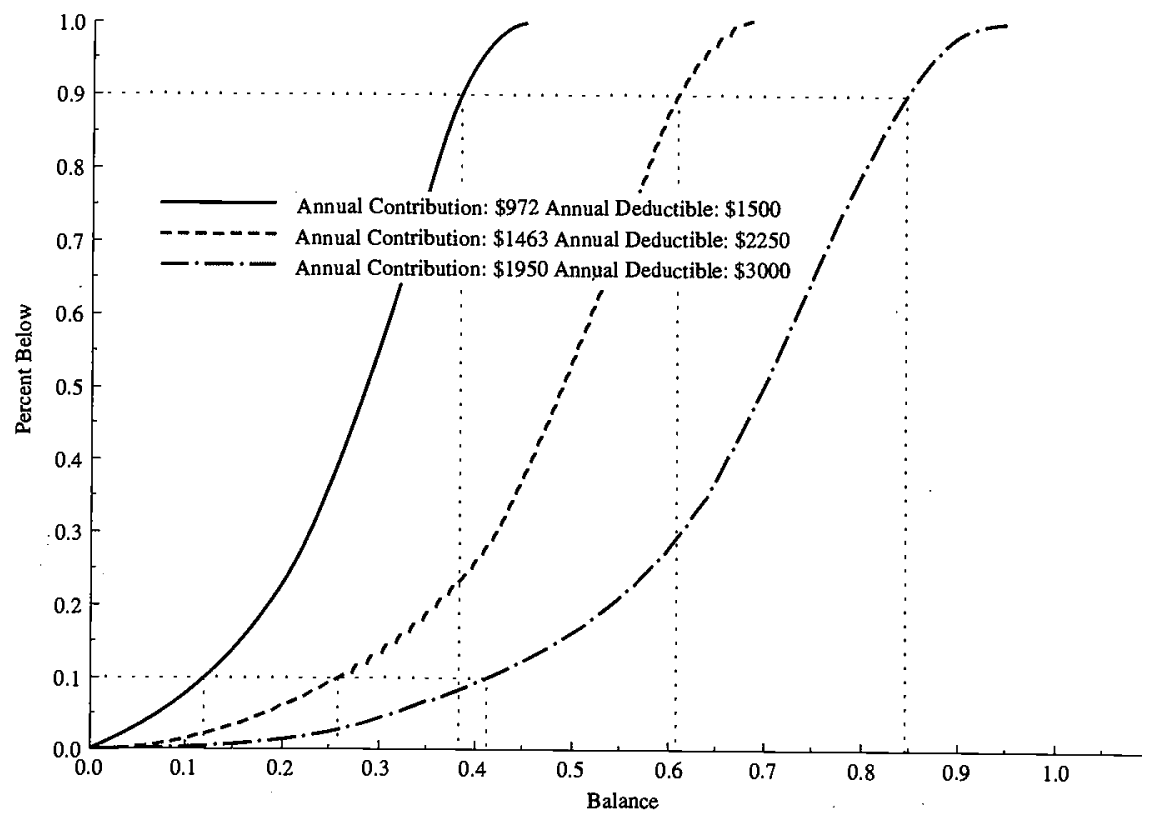

FIGURE 13: IHA Balances (Percent of Contributions) "KennedyKassebaum" MSA Provisions Salaried Males at Age 60

\section{TABLE 2}

Summary of MSA Balances at Age 60 Under EMW and Three Kennedy-Kassebaum Plans.

\begin{tabular}{|c|c|c|c|c|}
\hline \multirow[b]{2}{*}{ Description } & \multirow{2}{*}{$\begin{array}{l}\text { EMW } \\
\text { Base }\end{array}$} & \multicolumn{3}{|c|}{ "Kenney-Kassebaum" Plans } \\
\hline & & One & Two & Three \\
\hline Plan Deductible & $\$ 4,000$ & $\$ 1,500$ & $\$ 2,250$ & $\$ 3,000$ \\
\hline MSA Contribution & $\$ 2,000$ & $\$ 972$ & $\$ 1,463$ & $\$ 1,950$ \\
\hline \multicolumn{5}{|l|}{ MSA Balance at 60 : } \\
\hline $10 \%$ Below & $\$ 26,079$ & $\$ 8,560$ & $\$ 18,762$ & $\$ 30,234$ \\
\hline $10 \%$ Above & $\$ 60,988$ & $\$ 27,266$ & $\$ 43,617$ & $\$ 60,683$ \\
\hline \multicolumn{5}{|c|}{$\begin{array}{l}\text { MSA \% of Contributions } \\
\text { Remaining at } 60:\end{array}$} \\
\hline $10 \%$ Below & $36 \%$ & $12 \%$ & $26 \%$ & $42 \%$ \\
\hline $10 \%$ Above & $85 \%$ & $38 \%$ & $61 \%$ & $64 \%$ \\
\hline
\end{tabular}


tion of expenditures between one deductible and another. For example, the EMW Base plan assumes a $\$ 4,000$ deductible and the Kennedy-Kassebaum plan 2 assumes a $\$ 2,250$ deductible. The effect of this difference on expenditures depends on the proportion of total expenditures that fall in the $\$ 2,250$ to $\$ 4,000$ interval. Because only a small fraction of total expenditures falls in this interval, increasing the deductible does not increase expenditures enough to offset the large MSA contribution- $\$ 1,463$ versus $\$ 2,000$. Thus the percent of balances remaining at retirement is substantially higher in the EMS Base than in the Kennedy-Kassebaum plan 2. The large balances under the Kennedy-Kassebaum plans 2 and 3, relative to those under plan 1, are explained in a similar manner.

The EMW Base plan provides that if the MSA balance is zero, all expenses are paid by the insurance plan. The Kennedy-Kassebaum bill does not include such a provision; if the MSA balance is depleted, expenses are paid out-of-pocket, but not from the MSA. Table 3 shows that such out-of-pocket payments are likely to be very small. For example, under the Kennedy-Kassebaum plan 1, 96.68\% of persons age 25 to 29 have no such expenditures $1.32 \%$ have expenditures of $\$ 500$ or less, and $2 \%$ have expenditures between $\$ 501$ and $\$ 1,500$. There are no expenditures above $\$ 1,500$. The bulk of out-of-pocket expenditures are made by persons age 25 to 29 , who have had only a few years of MSA contributions. Such expenditures under plans 2 and 3 are even lower.

\subsection{Proportion of Cost Subject to Payment by Enrollee}

The principal reason that a catastrophic insurance plan is likely to reduce expenditures is that enrollees are using their own money (in the MSA) to pay for care. The simulations above do not take account of this behavioral response. We do not attempt to analyze that issue here, but we do present data that may help to place the issue in context. One way to get a rough idea of the proportion of costs that would be subject to full payment by the enrollee is to consider the proportion of annual individual expenditures that fall below the deductible. For example, in the Kennedy-Kassebaum plan 1, any person who incurred costs less than $\$ 1,500$ would pay all of those costs. The proportion of individual expenditures below selected levels, together with the proportion of individuals with expenditures below these levels, is shown in Figure 14. Although about $85 \%$ of individuals have expenditures below the Kennedy-Kassebaum plan 1 deductible, these enrollees account for a small fraction of total expenditures. Only about $12 \%$ of expenditures are below this level. About $25 \%$ of expenditures are below the EMW Base plan deductible of $\$ 4,000$ dollars. These proportions simply reflect an important feature of medical expenditures-a large fraction of costs 


\section{TABLE 3}

Kennedy-Kassebaum Out-of-Pocket Expenditure Not Paid from the MSA: Percent of Expenditure by Plan and by Age

\begin{tabular}{lcccr}
\multirow{2}{*}{$\begin{array}{l}\text { Age } \\
\text { Interval }\end{array}$} & \multicolumn{4}{c}{ Expenditure Interval } \\
\cline { 2 - 5 } & None & $\$ 0-\$ 500$ & $\$ 501-\$ 1500$ & $\$ 1501-\$ 500$ \\
$\begin{array}{l}\text { Kennedy-Kassebaum Plan 1: } \$ 1500 \text { Deductible and } \$ 972 \\
\text { Contribution }\end{array}$ & & & & \\
25-29 years & 96.68 & 1.32 & 2.00 & 0.00 \\
30-34 years & 99.76 & 0.18 & 0.06 & 0.00 \\
35-39 years & 99.80 & 0.14 & 0.06 & 0.00 \\
40-44 years & 99.74 & 0.18 & 0.08 & 0.00 \\
45-49 years & 99.58 & 0.16 & 0.26 & 0.00 \\
50-54 years & 99.38 & 0.24 & 0.38 & 0.00 \\
55-60 years & 99.40 & 0.33 & 0.27 &
\end{tabular}

Kennedy-Kassebaum Plan 2: \$2250 Deductible and \$1463 Annual MSA

Contribution

25-29 years

97.40

99.92

0.76

30-34 years

99.92

35-39 years

99.72

0.02

1.84

0.06

0.00

40-44 years

99.68

0.06

0.02

0.00

$45-49$ years

99.62

0.08

0.20

0.00

50-54 years

99.78

0.06

0.26

0.00

$55-60$ years

0.10

0.28

0.00

0.03

0.20

0.00

Kennedy-Kassebaum Plan 3: $\$ 3000$ Deductible and \$1950 Annual MSA

Contribution

$\begin{array}{lllll}25-29 \text { years } & 98.96 & 0.24 & 0.80 & 0.00 \\ 30-34 \text { years } & 99.94 & 0.00 & 0.06 & 0.00 \\ \text { 35-39 years } & 99.96 & 0.04 & 0.00 & 0.00 \\ 40-44 \text { years } & 99.88 & 0.00 & 0.12 & 0.00 \\ 45-49 \text { years } & 99.82 & 0.02 & 0.16 & 0.00 \\ \text { 50-54 years } & 99.80 & 0.06 & 0.14 & 0.00 \\ \text { 55-60 years } & 98.98 & 0.00 & 0.02 & 0.00\end{array}$

are accounted for by a small proportion of persons who incur very high costs in any one year. If the deductible were set much higher, say at $\$ 10,000$, about $45 \%$ of costs would be subject to full payment by the enrollee.

\section{OTHER IMPORTANT ISSUES FOR EVALUATING}

\section{MSAs}

In the analysis reported in Section 3, we assumed no behavioral responses to the change in incentives to use less medical care that the adoption of an MSA would provide, nor did we consider the effects of self-selection into 


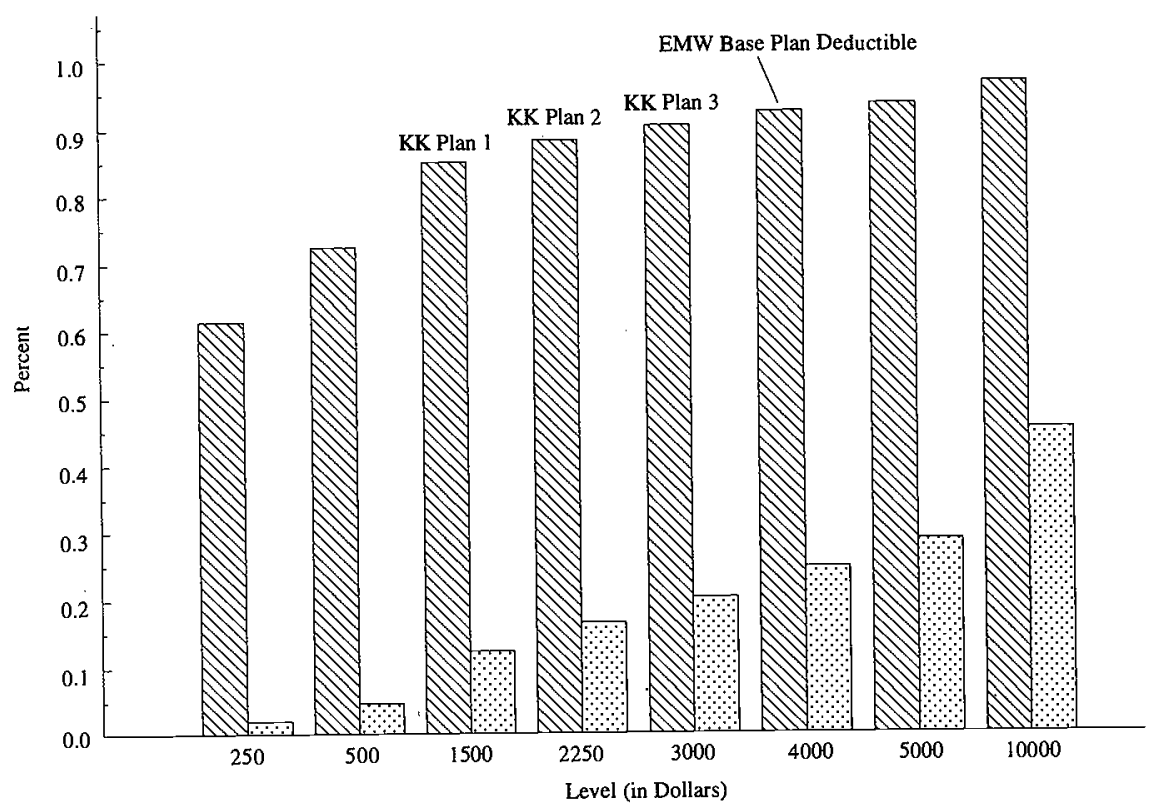

IIII Percentage of Individuals

Percentage of Expenditures

FIGURE 14: Percentage of Individuals and Expenditures Falling Below Specified Levels

MSAs when alternative plans are also offered to employees. Because MSAs have not yet been implemented, we have no direct evidence on how large these behavioral effects will be. Here, we outline some of the key behavioral questions for evaluating the effects of MSAs on medical expenditures and on the financial risk faced by individuals who might choose them. These questions are not unique to MSAs-indeed, they are important concerns for any type of health reform-but MSAs do present some distinctive features that we highlight.

\subsection{Sensitivity of Medical Spending to Changes in Price Incentives}

As Figure 1 suggested, over a large range of expenditures-from the level of the deductibles of the alternative plans to level of the OPM' of the MSA plan-individuals in MSAs will bear a substantially higher share of the cost of the medical care they consume. On the other hand, over some ranges the price of medical care will be lower. A reduction in aftertax price will occur for individuals who are "on the margin" at low 
expenditure levels that are below the deductible of the alternative plans. Assuming that (as current policies envision) MSAs rely more heavily on high deductibles than on copayments over a large range of expenditures, the reduction will also occur for sicker individuals who are "on the margin" above the expenditure level associated with the MSA's OPM, but below the expenditure level associated with the traditional plan's OPM. ${ }^{18}$ Finally, because the definition of medical expenses is broader under IRS tax law than in most existing health insurance plans, the MSA would lower the price of all expenditures on some types of medical care.

Because of such countervailing price effects, Keeler et al. (1996) conclude that the net effect of moving the non-elderly population of insured employees into MSAs would yield a modest but noticeable reduction in expenditures, on the order of $0 \%$ to $13 \%$. The American Academy of Actuaries (1995) reaches similar conclusions, predicting cost reductions in the range of $2 \%$ to $13 \%$. Nichols, Moon, and Wall (1996) estimate a slightly larger effect, around $15 \%$. These estimates were based on assumptions about the price sensitivity of different kinds of medical expenditures, drawing on results from the RAND Health Insurance Experiment (Buchanan et al., 1991), and from plan pricing methods used by the American Academy of Actuaries. Feldstein and Gruber (1995) have estimated considerably larger expenditure effects. They considered the adoption of MSAs with insurance plans that are considerably more "catastrophic" than those envisioned in the HIPAA. For example, one of their plans featured a deductible equal to $10 \%$ of family income, which is much larger than the HIPAA allows for higher-income families. They considered somewhat larger estimates of the price elasticity of demand for medical care. Many of the studies do not account for the tax subsidies the MSAs provide for outof-pocket medical expenditures and for services not covered in typical insurance plans.

Are the existing empirical estimates of price elasticity valid for evaluating MSAs? There is some evidence that creating a pool of the employee's "own" money may lead to larger effects than extrapolations from data on traditional insurance plans would suggest. For example, in recent

18 This situation is analogous to the countervailing incentive effects of quickly phasing out a low-income tax credit or welfare payment (and thereby providing more substantial distortions to a smaller share of potential workers) versus slowly (and thereby providing smaller distortions to a larger share). The type of MSAs described here provide relatively strong disincentives to overconsumption of health care at relatively low levels (e.g., up to $\$ 2000$ ), but the greater dependence on deductibles relative to copayments means that the disincentives go away early compared to plans with relatively greater reliance on copayments. Figure 1 illustrated this point, e.g., in the $\$ 2000$ to $\$ 4000$ range of expenditures. The optimal combination of deductibles and copayments in an MSA plan is another important empirical question. 
years Dominion Resources has created an "account" for health care costs; if firm expenditures end up below the budget amount, employees who did not exceed the plan deductible receive a share of the surplus. In the plan's first year, costs were $31 \%$ under budget, suggesting a substantial effect from creating the pool (American Academy of Actuaries, 1995). Whether employees would spend money from their own account more carefully than under a traditional insurance plan with copayments is an unresolved question in general.

Similarly, are the MSA tax incentives of the HIPAA optimal for improving efficiency? For example, would some form of tax credits coupled with limitations on the deductibility of expenditures represent a better targeting of tax expenditures? Should the MSA be available for use in conjunction with managed-care plans? Few simulations and even less empirical evidence exists on such important details of MSA-related tax reforms.

Further research on these questions would be helpful for determining the optimal structure of an MSA plan. Some analysts will probably conclude that the rather low "sub-catastrophic" limits on out-of-pocket spending in the HIPAA do not permit a full evaluation of the potential gains from MSA plans. Higher deductibles and out-of-pocket maximums, as some analysts have supported, could subject a much larger share of medical expenditures to payment with individuals' own money, requiring MSA withdrawals, rather than payment by a health insurance plan, perhaps leading to larger efficiency gains. But greater personal liability might discourage individuals who expect significant expenditures from signing up for MSAs, relative to the MSAs in HIPAA. In any case, it is unlikely that evidence from the HIPAA "experiment" alone will resolve these issues.

\subsection{Plan Selection Effects}

No recent legislation and few firms have proposed compulsory enrollment in an MSA plan. When MSAs are offered in conjunction with alternative traditional fee-for-service or managed-care insurance plans, the consequences for medical expenditures will also depend on the proportion of medical costs that are paid for with enrollees own money out of their MSA accounts. As the discussion in Section 2 and our analysis of persistence in Section 3 suggested, MSAs will look attractive to the very healthy, but in many realistic circumstances they may also seem advantageous to those expecting very high expenditures. Indeed, in simulations that implicitly accounted for the "safety valve" effect, Keeler et al. (1996) observed only modest adverse selection for plans with relatively low catastrophic deductibles, in the range envisioned by the HIPAA. As we 
noted previously, however, simulations reported to date show that alternative assumptions about the extent to which the healthy will select an MSA can have a substantial impact on the predicted savings. In addition, the deductibility of MSA withdrawals in the HIPAA means that the net incentive to join an MSA increases substantially with income; the magnitudes of this income effect on MSA selection and spending are not known.

\subsection{Costs of Risk Bearing}

To the extent that individuals do face higher after-tax prices when they are ill, they lose the benefits of income smoothing that more generous insurance would provide. Based on fairly generous assumptions about how risk-averse individuals are to income disruptions of several thousand dollars per year, Pauly (1994) and Keeler et al. (1996) conclude that the "insurance cost" of MSAs such as those envisioned in the HIPAA was likely to be modest in any given year. Our simulations suggest that, at least for the vast majority of the nonelderly population, they are also modest over longer time periods, even for MSAs that impose considerably more liability for medical expenses. On the other hand, MSAs to date have not been very popular as an approach to limiting medical spending. An important empirical question is the extent to which tax subsidies to encourage the establishment of MSAs and to remove the tax wedge between plans that use supply-side and demand-side incentives will affect plan choice behavior.

\subsection{Nonmedical Incentives to Join MSAs}

Because individuals who do not spend MSA balances on medical care may use the funds for other purposes, MSA tax incentives may provide a shelter for accumulating additional savings. The penalties for withdrawal before age 65 limit the value of the tax break for the nonelderly, but they may be attractive for individuals who otherwise would have to face high marginal tax rates on earnings or who have exhausted other tax shelters for retirement savings. To illustrate, consider an individual in a 50\% marginal tax bracket who joins the MSA described in Section 2 and remains in it for 30 years (until he withdraws it without penalty at age 65), earns a real return of $5 \%$ on the MSA balance, and has $\$ 800$ per year in medical expenditures. Because he can contribute $\$ 1300$ of pretax income to the MSA each year, he will accumulate $\$ 20,930$ in after-tax savings upon withdrawal. In contrast, a pretax contribution of $\$ 500$ to a regular savings account with taxable interest would only have led to an accumulation of $\$ 14,700$. Because the accumulation difference increases with both the magnitude of the allowed contribution and the tax rate, the Kennedy-Kassebaum MSAs will be relatively attractive to higher- 
income individuals, not only because of the lower after-tax price of medical expenditures but also because of the greater gain from savings.

The relatively stringent caps on annual MSA contributions in the Kennedy-Kassebaum bill imply that individuals should not be able to enjoy huge gains in savings accumulations from the tax break. However, allowing higher out-of-pocket limits and MSA contributions would accentuate these tax differences. Would the resulting MSA accumulations represent new savings, or simply a relabeling of retirement savings in response to the tax break? The weight of the evidence is that the bulk of IRA and 401(k) retirement saving plan contributions have been net new saving (Poterba, Venti, and Wise, 1996a, 1996b). Whether the same would be true of the MSA is not clear. It would depend, for example, on whether the MSA were set up independently of existing retirement saving plans. In that case, the existing evidence suggests that it would induce new saving. Even if these savings were "new," they would come at a cost in tax expenditures associated with the MSA provisions. The magnitudes of these effects on savings and tax expenditures have not been assessed.

\subsection{Transition Costs}

Because relatively few employees have existing buffers of savings for medical or other unexpected out-of-pocket expenses, MSA plans are likely to appear less attractive to many workers at the outset than they would once some savings were accumulated in them. For example, employees might be substantially more likely to join an MSA plan that gives them an initial balance equal to the catastrophic plan's out-of-pocket maximum when they first join. Since most employees would not spend the full balance in the first year, they would become "locked in" to the MSA: the penalty for withdrawing the balance lowers the cost of continuing in the MSA relative to switching to another plan. Such one-time incentives might be very helpful in encouraging takeup of MSAs, but evidence on the magnitude of such liquidity effects will not come from the HIPAA, in which only a fixed fraction of the out-of-pocket maximum may be contributed in any year.

\subsection{Effects on Expenditure Growth}

Simulations of MSA plans to date have modeled one-time effects on medical expenditures. To have a consequential long-term impact on medical costs, MSAs must affect expenditure growth as well. The currently low rate of enrollment in catastrophic plans and the limited scope of the HIPAA bill implies that MSAs in the near future are unlikely to cause systematic changes in medical practice. Thus the limited use of 
these plans will probably have no effect on the principal determinant of long-term expenditure growth-technological change. In contrast, as managed-care plans have become widespread, they appear to have led to systemic effects on medical expenditure growth. Because MSAs are unlikely to become nearly so widespread in the near future, evidence on the comparative performance of MSAs relative to supply-side incentives is unlikely to emerge in the near future.

\section{CONCLUSION}

We have analyzed MSA plans, focusing on the provisions and incentives inherent in the Health Insurance Portability and Availability Act. The analytic core of the paper suggests that persistence in individual medical expenditures does not present an important roadblock to the feasibility of MSA plans. Over a working lifetime, our simulations suggest that MSA reforms are unlikely to have substantial adverse consequences for the vast majority of nonelderly employees. The persistence of high medical expenditures does not appear to be a major obstacle to the widespread adoption of MSA plans. In future work, we intend to explore in detail the consequences of MSA reforms for the small fraction of individuals who do face high expenditures year after year. We also noted that adverse selection problems might be less extensive with MSA options than in situations where employees are allowed to choose among managed-care plans only. Many other considerations are also important in determining the potential of MSAs to improve efficiency in health care. We discussed some of these difficult issues to highlight the additional evidence that is needed for a more comprehensive evaluation of MSAs.

These considerations suggest that, while the MSA provisions in the HIPAA will provide some important insights into how MSAs will work in practice, they will not permit a complete analysis of many of the key empirical issues that will determine the effectiveness of potential MSAs. The HIPAA insurance plans will generally be sub-catastrophic, and so they can provide only limited information about how truly catastrophic plans would work. In addition, the HIPAA allows only a limited number of MSA accounts to be established, so that the MSAs cannot have systemic effects on medical practice, as managed care is having now. Further, compared to existing insurance plans, the net effect of taking up one of the new MSAs on the after-tax price of medical care is likely to be relatively small. Large differences across MSA enrollees in asset accumulations are also unlikely. As a result, the HIPAA is probably best regarded as an initial partial test of the feasibility of MSA plans: Will they be taken up, and if so by whom? Will there be disastrous consequences 
for the health or financial status of those who join and for others in their firms or risk pools? We suspect that the new MSA plans in HIPAA will be reasonably attractive to eligible individuals, especially those in higher tax brackets and who face high premiums now, and that the consequences of their switching to these MSA plans will be modest.

\section{REFERENCES}

American Academy of Actuaries (1995). "Medical Savings Accounts: Cost Implications and Design Issues." Washington, DC: AAA Public Policy Monograph Series, May 1995.

Arrow, Kenneth (1963). "Uncertainty and the Welfare Economics of Medical Care" 53(5):941-973

Buchanan, Joan L. et al. (1991). "Simulating Health Expenditures Under Alternative Insurance Plans." Management Science 37:1067-1090.

Eichner, Matthew J., Mark B. McClellan, and David Wise (1996). "Insurance or Self-Insurance?: Variation, Persistence, and Individual Health Accounts". NBER Working Paper no. 5640.

Feldstein, Martin F., and Jonathan Gruber (1995). "A Major Risk Approach to Health Insurance Reform" In Tax Policy and the Economy, vol 9, James M. Poterba (ed.). Cambridge, MA: MIT Press.

Gramm, Phil (1994). "Why We Need Medical Savings Accounts." New England Journal of Medicine 330:1752-1753.

Keeler, Emmett B., Jesse D. Malkin, Dana P. Goldman, Joan L. Buchanan (1996). "Can Medical Savings Accounts for the Nonelderly Reduce Health Care Costs?" JAMA 275(21):1666-1671.

Levit, Katherine R., Helen C. Lazenby, and L. Sivarajan (1996). "Health Care Spending in 1994: Slowest in Decades." Health Affairs 15(2):130-144.

Moon, Marilyn, Len M. Nichols, and Susan Wall (1996). "Medical Savings Accounts: A Policy Analysis." Urban Institute, Washington, DC. Mimeograph.

Nichols, Len M., Marilyn Moon, and Susan Wall (1996). "Tax-Preferred Medical Savings Accounts and Catastrophic Health InsurancePlans: A Numerical Analysis of Winners and Losers" Urban Institute, Washington, DC. Mimeograph. Pauly, Mark V. (1994) An Analysis of Medical Savings Accounts: Do Two Wrongs Make a Right? Washington, DC: American Enterprise Institute. Monograph. and John C. Goodman (1995). "Tax Credits for Health Insurance and Medical Savings Accounts." Health Affairs 14(2):126-139.

Poterba, James M., Steven F. Venti, an r David A. Wise (1996a). "How Retirement Savings Programs Increase Saving." Journal of Economic Perspectives 10(4) (November):91-112.

(1996b). "Personal Retirement Saving Programs and Asset Accumulation: Reconciling the Evidence." NBER Working Paper no. 5599.

Price, James R. and James W. Mays (1985). "Selection and the Competitive Standing of Health Plans in a Multiple-Choice, Multiple-Insurer Market." In Advances in Health Economics and Health Services Research, vol. 6, Richard M. Scheffler and Louis R. Rossiter, (eds.).

Zwanziger, Jack, and Glenn A. Melnick (1996). "Can Managed Care Plans Control Health Care Costs?" Health Affairs 15(2):185-199. 